\title{
TNF/TNFR axis promotes pyrin inflammasome activation and distinctly modulates pyrin inflammasomopathy
}

\author{
Deepika Sharma, ${ }^{1}$ Ankit Malik, ${ }^{1}$ Clifford Guy, ${ }^{1}$ Peter Vogel,, ${ }^{2}$ and Thirumala-Devi Kanneganti' \\ 'Department of Immunology and ${ }^{2}$ Animal Resources Center and the Veterinary Pathology Core, St. Jude Children's Research Hospital, Memphis, Tennessee, USA.
}

\begin{abstract}
Pyrin is an inflammasome sensor that promotes caspase-1-mediated pyroptotic cell death and maturation of proinflammatory cytokines IL-1 $\beta$ and IL-18. Familial Mediterranean fever (FMF), an autoinflammatory disorder, is associated with mutations in the gene encoding pyrin (MEFV). FMF-knockin (FMF-KI) mice that express chimeric pyrin protein with FMF mutation (Mefv ${ }^{V 726 A / V 726 A}$ ) exhibit an autoinflammatory disorder mediated by autoactivation of the pyrin inflammasome. Increase in the levels of TNF are observed in FMF-KI mice, and many features of FMF overlap with the autoinflammatory disorder associated with TNF receptor signaling. In this study, we assessed the contribution of TNF signaling to pyrin inflammasome activation and its consequent role in distinct FMF pathologies. TNF signaling promoted the expression of pyrin in response to multiple stimuli and was required for inflammasome activation in response to canonical pyrin stimuli and in myeloid cells from FMF-KI mice. TNF signaling promoted systemic wasting, anemia, and neutrophilia in the FMF-KI mice. Further, TNF-induced pathology was induced specifically through the TNFR1 receptor, while TNFR2-mediated signaling was distinctly protective in colitis and ankle joint inflammation. Overall, our data show that TNF is a critical modulator of pyrin expression, inflammasome activation, and pyrin-inflammasomopathy. Further, specific blockade of TNFR1 or activation of TNFR2 could provide substantial protection against FMF pathologies.
\end{abstract}

\section{Introduction}

Familial Mediterranean fever (FMF) is an autoinflammatory disorder with autosomal-recessive inheritance and high prevalence in ethnic groups overly represented in the Mediterranean basin, including Jewish, Armenian, Arab, and Turkish populations (1). It is characterized by episodic fever, neutrophilia, and inflammation of the serosal tissues, including pleural, and peritoneal cavities and joints. FMF is caused by mutations in the gene encoding pyrin, also known as MEFV or marenostrin $(2,3) . M E F V$ translates into a protein of 781 amino acids with an N-terminal pyrin (PYD), a central boxed-box and coiled-coil (BBCC) domain, and a C-terminal PRY/SPRY (B30.2) domain (4). Nearly one-third of mutations identified in FMF patients are localized to exon 10 (https://infevers.umai-montpellier.fr/ web/search.php?n=1), which encodes for the B30.2 domain. This domain, however, is not found in the murine ortholog (5). Pyrin was recently identified as an innate sensor that nucleates ASC and caspase- 1 to form the multimeric inflammasome complex $(6,7)$. Processing of caspase- 1 through the inflammasome complex", i.e., is it the processing itself that leads to maturation of inflammatory cytokines, IL-18, and IL-1 $\beta$, and induction of pyroptotic cell death $(8,9)$. The murine model of FMF involves generation of FMF-knockin (FMF-KI) mouse strain that expresses a

Conflict of interest: The authors have declared that no conflict of interest exists. License: Copyright 2019, American Society for Clinical Investigation.

Submitted: March 28, 2018; Accepted: October 9, 2018.

Reference information: J Clin Invest. 2019;129(1):150-162.

https://doi.org/10.1172/JCl121372. chimeric pyrin protein containing the human B30.2 domain with a mutation associated with FMF (5). The FMF-KI strain, represented as Mefiv ${ }^{\mathrm{v} 726 \mathrm{~A} / \mathrm{V} 726 \mathrm{~A}}$, develops an autoinflammatory disorder characterized by systemic wasting and neutrophilia, which is caused by gasdermin-D-mediated IL- $1 \beta$ release in response to aberrant pyrin inflammasome activation $(5,10,11)$. Further, the disorder is mediated through hematopoietic cells, suggesting that pyrin dysfunction is intrinsic to the cells of the immune system (5). Unlike FMF-KI mice, pyrin-deficient mice do not exhibit an overt developmental or inflammatory defect, but do exhibit reduced epithelial integrity during mucosal damage (12). Therefore, regulation of pyrin inflammasome during autoinflammatory disorders is critical to maintenance of homeostasis.

Gene expression analysis suggests that pyrin is highly expressed in leukocytes during all stages of development and that its expression is significantly promoted by inflammatory mediators, including TNF (3, 12-15). TNF signaling is frequently observed to be heightened in patients with FMF (16-19) and in the mouse model of FMF (10). Clinical features of FMF also overlap with TNF receptorassociated periodic syndrome (TRAPS), a class of autoinflammatory disorders associated with mutations in the TNF receptor (20), and anti-TNF biologics have been used in patients with FMF (21-25). These observations suggest that TNF signaling could play an important role in pyrin inflammasomopathy.

TNF is expressed by multiple cells of the innate and adaptive immune systems and by nonimmune cells, such as endothelial cells and fibroblasts (26). TNF exists in 2 forms - membrane-bound TNF (mTNF, $26 \mathrm{KDa}$ ) and soluble TNF (sTNF, $17 \mathrm{KDa}$ ), which is produced by TNF- $\alpha$-converting enzyme-mediated (TACE-mediated) cleav- 
age of the proform. Both forms of TNF signal through 2 transmembrane receptors, TNFR1 and TNFR2 (27). Membrane-bound TNF is a potent ligand for TNFR2 that is expressed mostly by immune cells (27). On the other hand, TNFR1 is expressed at low levels by most cell types and can respond to both membrane-bound and soluble forms of TNF. Cell death and inflammatory cytokine production in response to TNF signaling is induced primarily by TNFR1 signaling (28-31), while the precise role of TNFR2 is relatively unclear (32, 33). TNFR2 has been shown to promote TNFR1-mediated cell death signaling $(29,34,35)$ and, in other cases, to promote cell survival, proliferation, and tissue homeostasis (36-40).

In this manuscript, we highlight the central role of TNF signaling in pyrin inflammasome activation and in FMF pathology. TNF played a critical role in promoting expression and activation of pyrin and in the development and amplification of the inflammatory disorder observed in the FMF-KI mice. Further, we demonstrate a pathogenic role of TNFR1 and a distinct, protective role of TNFR2 signaling in FMF pathologies. Overall, the study highlights the specific roles of the TNF/TNFR axis in regulating the pyrin inflammasome and the distinct features of pyrin inflammasomopathy.

\section{Results}

$T N F$ promotes pyrin expression and inflammasome activation. To investigate the role of TNF signaling in pyrin inflammasome activation, we stimulated WT, $\operatorname{Tnf}{ }^{\gamma^{-}}$, and $\operatorname{Tn} f r 1^{-/-} \operatorname{Tn} f \mathrm{r}^{-/-}$BM-derived macrophages (BMDMs) with Clostridium difficile toxin B, a canonical pyrin-activating stimulus (7). BMDMs deficient in TNF signaling ( $\mathrm{Tnf}^{/-}$and $\mathrm{Tnfr}^{-/}$) exhibit reduced inflammasome activation, as assessed by lower caspase-1 cleavage, IL-1 $\beta$ maturation, and lactate dehydrogenase (LDH) release consequent to pyroptotic cell death (Figure 1, A-C, and Supplemental Figure 1A; supplemental material available online with this article; https://doi.org/10.1172/ JCI121372DS1). Pyrin expression was significantly upregulated in response to $C$. difficile toxin stimuli, and this upregulation was mediated by the TNF/TNFRaxis (Figure1D). To determine whether C. difficile toxin itself induces TNF production, we assessed the level of TNF transcripts and observed upregulation of TNF mRNA in response to the stimuli (Supplemental Figure 1B). TNF mRNA was upregulated even in response to commercially available purified toxin (C. difficile toxin B [TcdB]), in accordance with prior reports (41) (Supplemental Figure 1C). Further, Tnf ${ }^{--}$and Tnfr- $^{--}$BMDMs responded with lower caspase-1 processing, IL-18 release, and pyroptotic cell death following purified toxin (TcdB) stimuli (Supplemental Figure 1, D-F). These data demonstrate the critical role of TNF signaling in pyrin inflammasome activation.

Pyrin upregulation in response to multiple microbial ligands and cytokine stimuli has been reported previously (15). We therefore assessed whether TNF signaling is central to pyrin upregulation in response to other TLR and cytokine stimuli. Pyrin expression was significantly upregulated by multiple inflammatory stimuli, including LPS, Pam3CSK4, polyinosinic:polycytidylic acid (poly[I:C]), and gardiquimod, and this upregulation was significantly lower in the absence of TNF/TNFR signaling (Figure 1E). Expression of NLRP3, another inflammasome sensor, and cytokine IL-1 $\beta$, on the other hand, were induced in a manner independent of TNF signaling in response to the same stimuli (Figure 1E). Further,
NLRP3 inflammasome activation and subsequent IL-1 $\beta$ release in response to canonical NLRP3 triggers ATP, nigericin, and silica were independent of TNF signaling (Figure 1, F and G). We also tested to determine whether activation of other inflammasomes, NLRC4 and AIM2, was affected by TNF signaling. Caspase-1 processing and IL-1 $\beta$ release were similar among WT, TNF, and TNFR-deficient BMDMs in response to NLRC4 triggers Salmonella and Pseudomonas and the AIM2 trigger-transfection of DNA analog poly(deoxyadenylic-deoxythymidylic) (poly[dA:dT]) (Supplemental Figure 2). These data demonstrate that the TNF/TNFR axis is specifically required to promote pyrin inflammasome activation. Similarly to TLR stimuli, TNF directly induced pyrin expression in WT BMDMs (Figure 2A). IFN- $\beta$ stimuli promoted Tnf upregulation (Figure 2B) and induced pyrin expression via TNF signaling (Figure 2A). The critical role of TNF/TNFR in pyrin expression was additionally observed in peritoneal macrophages under unstimulated conditions and in response to LPS, Pam3CSK4, or IFN- $\beta$ stimuli (Figure 2C).

Next, we assessed whether TNF signaling was also involved in the overt pyrin inflammasome activation observed in Mefiv ${ }^{\mathrm{V} 726 \mathrm{~A} / \mathrm{V} 726 \mathrm{~A}}$ cells (10). LPS stimuli induced inflammasome activation in $M e f v^{\mathrm{v} 726 \mathrm{~A} / \mathrm{V7} 26 \mathrm{~A}}$ monocytes, as assessed by caspase- 1 cleavage and IL-1 $\beta$ release (Figure 2, D-G). Both parameters of inflammasome activation were significantly abrogated in the absence of the TNF signaling axis (Figure 2, D-G). Similar to the observations with BMDMs, pyrin expression in Mefv ${ }^{\mathrm{v} 726 \mathrm{~A} / \mathrm{V7} 26 \mathrm{~A}}$ monocytes was also promoted by the TNF/TNFR axis (Figure 2, D and F). Overall, these data highlight a central role for TNF in synergizing with multiple stimuli (microbial and IFN- $\beta$ ) to promote pyrin expression and inflammasome activation.

$T N F$ promotes runting and systemic inflammation in FMF mice. We have previously identified inflammasome-mediated IL-1 $\beta$ production as an instigator of pathology in $M e f v^{\mathrm{V726A} / \mathrm{V} 726 \mathrm{~A}}$ mice. Alongside IL-1 $\beta$, levels of TNF were also significantly elevated in the Mefv $v^{\mathrm{V} 726 \mathrm{~A} / \mathrm{V} 726 \mathrm{~A}}$ mice in comparison with control Mefv ${ }^{\mathrm{V} 726 \mathrm{~A} /+}$ mice (Figure 3A), which is consistent with previous reports (5). As TNF signaling was involved in pyrin inflammasome activation (Figures 1 and 2), we assessed the contribution of TNF signaling in the FMF disease model by generating $M e f v^{\mathrm{V} 726 \mathrm{~A} / \mathrm{V} 726 \mathrm{~A}}$ mice that lack TNF or its receptors, TNFR1 and TNFR2. Loss of TNF signaling provided significant protection against runting, a trait observed in Mefiv $v^{\mathrm{V} 26 \mathrm{~A} / \mathrm{V726A}}$ mice (10) (Figure 3, B and C). $M e f v^{\text {V726A/V726A }}$ mice lacking TNF or both TNFR1 and TNFR2 gained significantly more weight as compared with the Mefiv $v^{\mathrm{V} 26 \mathrm{~A} / \mathrm{V} 726 \mathrm{~A}}$ mice (Figure 3, B and C).

Chronic inflammation is a major driver of systemic wasting, and increased levels of inflammatory mediators are observed in the serum of $M e f v^{\mathrm{V} 726 \mathrm{~A} / \mathrm{V} 726 \mathrm{~A}}$ mice (5). To assess the role of TNF signaling in promoting systemic inflammation, we assessed the level of cytokines and chemokines in the sera of various strains of $M e f v^{\mathrm{V} 726 \mathrm{~A} / \mathrm{V} 726 \mathrm{~A}}$ mice. Production of certain inflammatory mediators, such as IL-1 $\beta$, MIP- $1 \alpha$, and GM-CSF, was significantly elevated in $M e f v^{\mathrm{V} 726 \mathrm{~A} / \mathrm{V} 726 \mathrm{~A}}$ mice and blunted in the absence of TNF

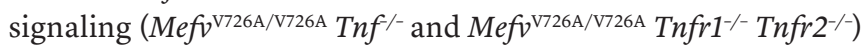
(Figure 3D). Other inflammatory mediators, such as IL-6, G-CSF (granulocyte-colony stimulating factor), IL-17, KC, and $\mathrm{MCP}-1$, were significantly higher in $M e f v^{\mathrm{V} 726 \mathrm{~A} / \mathrm{V} 726 \mathrm{~A}}$ mice and not 
A

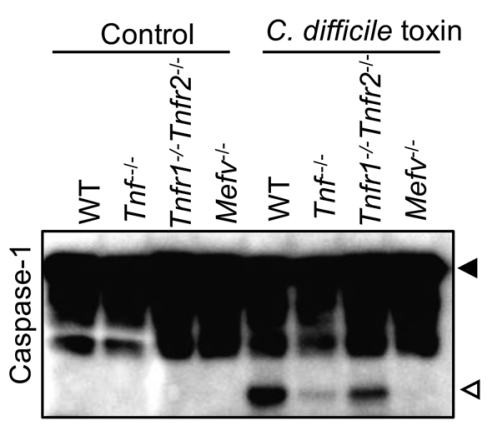

D

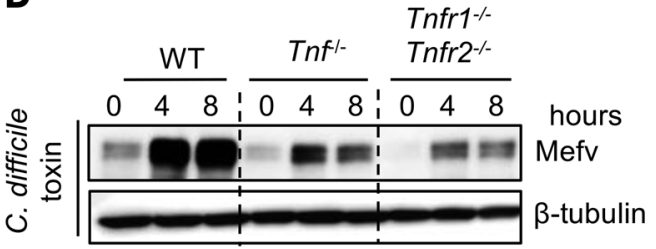

$\mathbf{F}$
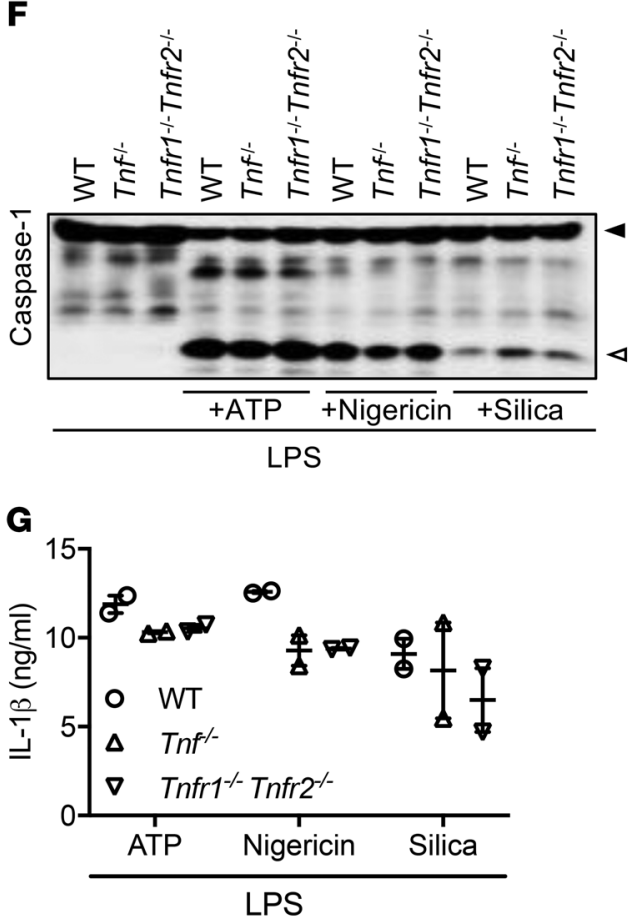

B

- WT $>$ Tnfr1 $^{--}$Tnfr2 $^{--}$

- Tnf $^{\prime-}$ O Mefv'

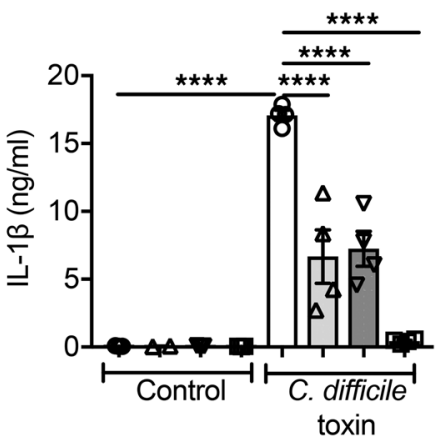

C

- WT $>$ Tnfr $^{-1-T n f r} 2^{-1-}$

- $\mathrm{Tnf}^{-1}$ ○ Mefv'-

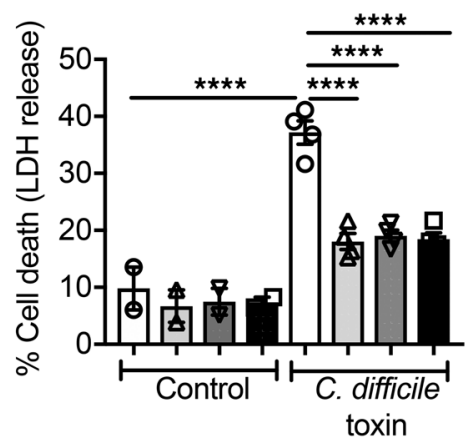

E

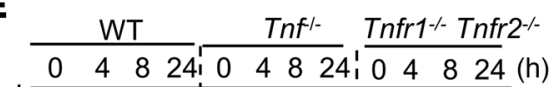

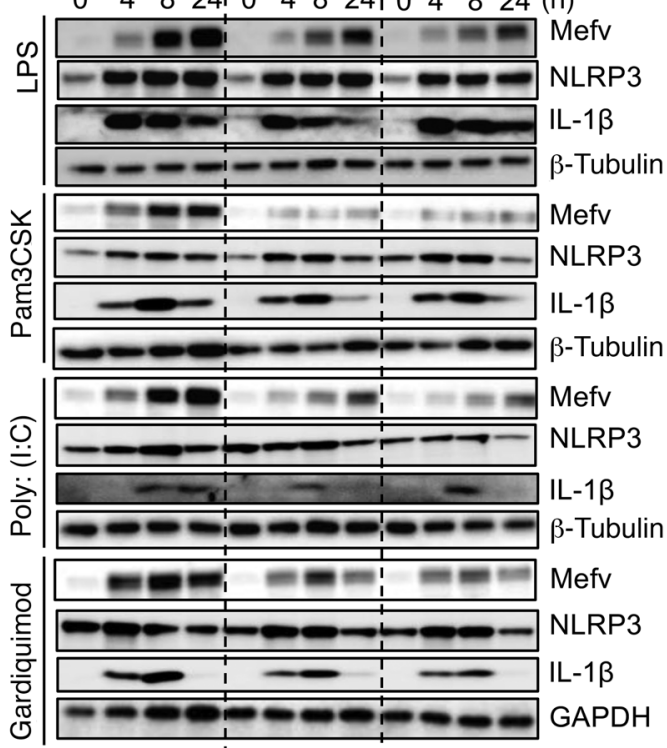


A

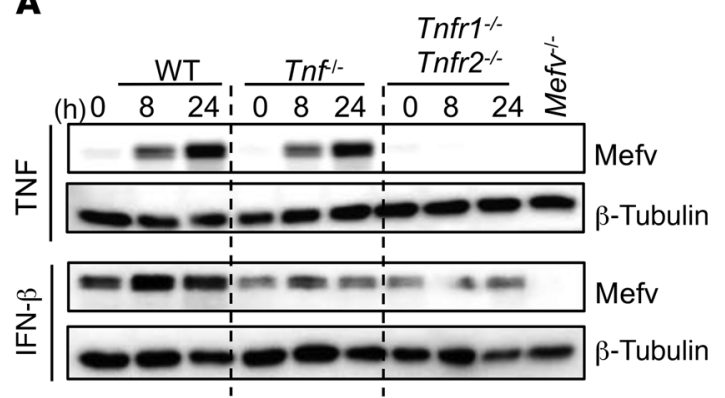

B

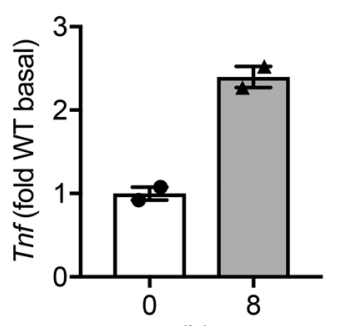

(h)
C

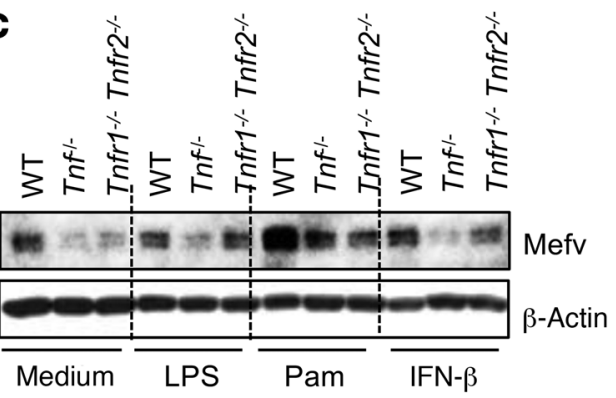

D

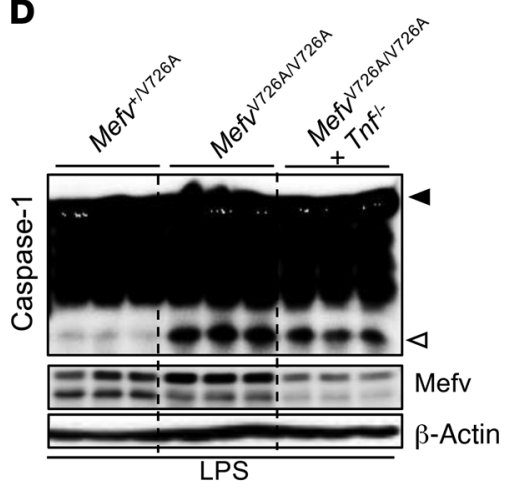

G

- Mefv ${ }^{+N 726 A}$

- Mefvi26AN726A

$\nabla$ Mefv ${ }^{V 726 A N 726 A} \times$ Tnfr1 $^{-1} \times$ Tnfr2 $^{-1-}$

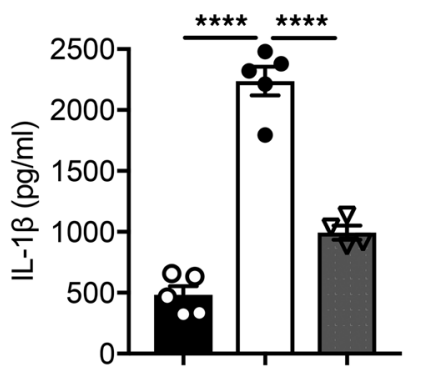

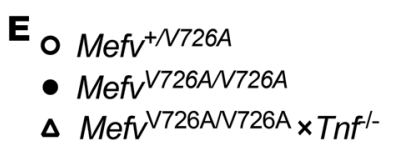

$\Delta$ MefvV726AN726A $\times$ Tnf $^{-}$

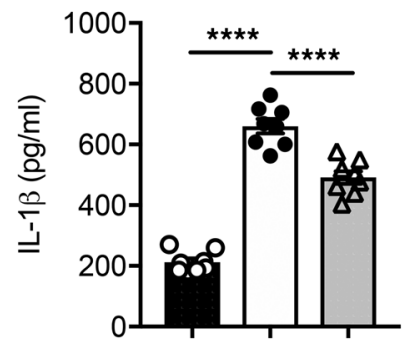

$\mathbf{F}$

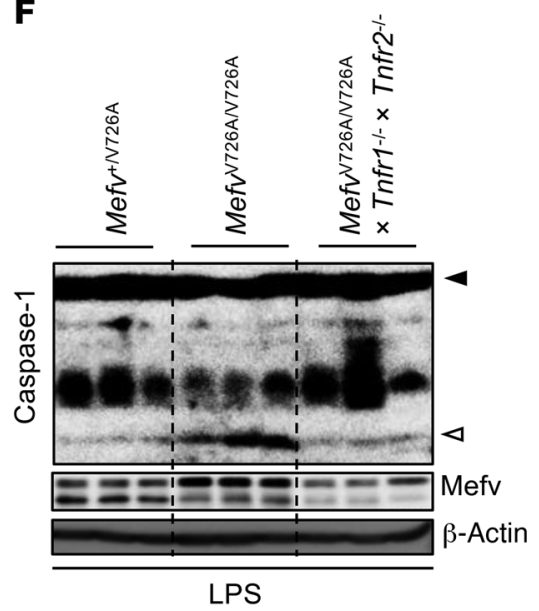

Figure 2. Pyrin activation observed in Mefv ${ }^{\mathrm{V726A} / \mathrm{V726A}}$ monocytes is promoted by TNF signaling. Pyrin expression in (A) BMDMs and (C) peritoneal cells following TLR and cytokine stimuli (TNF, IFN- $\beta$ ) over 24 hours. (B) Tnf expression in WT BMDMs stimulated with IFN- $\beta$. (D and F) Caspase-1 processing, pyrin expression, and (E and $\mathbf{G})$ IL-1 $\beta$ release in monocytes in response to LPS (200 ng/ml) stimuli for 24 hours. (B, E, G) Data are presented as mean \pm SEM and are representative of at least 3 independent repeats. ${ }^{* * *} P<0.0001$ compared with Mefv ${ }^{\mathrm{V} 726 \mathrm{~A} / \mathrm{V} 726 \mathrm{~A}}, 1$-way ANOVA followed by Fischer's LSD test. all, these data suggest that the TNF/TNFR axis promotes various features of FMF disease, including systemic wasting, inflammation, and anemia.

TNF is a critical driver of neutrophilia and granulopoiesis observed in Mefv ${ }^{V 726 A / V 726 A}$ mice. Systemic neutrophilia is one of the hallmarks of FMF $(1,5)$, and TNF has been shown to directly promote myelopoiesis (49). Neutrophilia, as ascertained by the proportion and number of circulating neutrophils, was significantly reduced in the absence of TNF signaling in Mefv ${ }^{\mathrm{V} 726 \mathrm{~A} / \mathrm{V} 726 \mathrm{~A}}$ mice (Figure 4, A and B, and Table 1). Mefiv ${ }^{\mathrm{V} 726 \mathrm{~A} / \mathrm{V7} 26 \mathrm{~A}}$ mice further exhibited extramedullary granulopoiesis in the liver (Figure $4 \mathrm{C}$ ) and spleen (Figure 4D) that was also significantly reduced in the absence of TNF signaling. While loss of TNF signaling did not protect against splenomegaly (Figure $4 \mathrm{E}$ ), the proportion and number of granulocytes (Figure 4, D and E, and Supplemental Figure 3 ) in the spleen were significantly reduced in the absence of TNF signaling in $M e f v^{\mathrm{v} 726 \mathrm{~A} / \mathrm{V} 726 \mathrm{~A}}$ mice. Spleens from $M e f v^{\mathrm{v} 726 \mathrm{~A} / \mathrm{V} 726 \mathrm{~A}}$ mice also exhibited altered cellular composition, characterized by loss of lymphocytes (both B and T cells) (Figure 4D and Supplemental Figure 3). Genetic loss of TNF and TNFR markedly rescued the altered cellularity, as the proportion of $\mathrm{B}$ and $\mathrm{T}$ cells was elevated

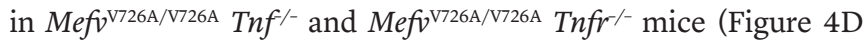
and Supplemental Figure 3). These data demonstrate that neutrophilia and extramedullary granulopoiesis in $M e f v^{\mathrm{V} 726 \mathrm{~A} / \mathrm{V} 726 \mathrm{~A}}$ mice are specifically promoted through TNF signaling.

Neutrophilia in FMF mice is driven by hematopoietic cells (5), and since TNF is a critical driver of neutrophilia (Figure 4), we assessed whether TNF production by or TNFR signaling within the hematopoietic compartment was required to drive neutrophilia in Mefv ${ }^{\mathrm{V} 726 \mathrm{~A} / \mathrm{V} 726 \mathrm{~A}}$ mice. To address this, we generated BM chimeras with WT mice as recipients and Mefivi26A/+, Mefiv ${ }^{\mathrm{V} 726 \mathrm{~A} / \mathrm{V} 726 \mathrm{~A}}$, $M e f v^{\mathrm{V} 726 \mathrm{~A} / \mathrm{V726 \textrm {A }}} \mathrm{Tnf}^{\prime-}$, and Mefvi ${ }^{\mathrm{V} 726 \mathrm{~A} / \mathrm{V} 726 \mathrm{~A}} \mathrm{Tnfr}^{-/}$as donors. Reconstitution of irradiated WT mice with Mefiv $v^{\mathrm{V} 726 \mathrm{~A} / \mathrm{V} 726 \mathrm{~A}}$ (but not Mefiv ${ }^{\mathrm{V} 726 \mathrm{~A} /+}$ ) BM cells induced neutrophilia (Supplemental Figure 4, A and B). This neutrophilia was significantly reduced in mice reconstituted with TNF-deficient BM cells (MefviveA/V726A $\operatorname{Tnf}^{\mathrm{V} /-}>>\mathrm{WT}$ ), but not 
A

- Mefv $+N 726 A$
- Mefv V726AV726A

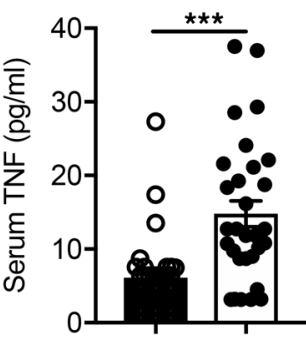

D

- Mefv $v 726 \mathrm{~A}+$

$\Delta$ Mefv V726AV726A $\times$ Tnf $^{\prime-}$
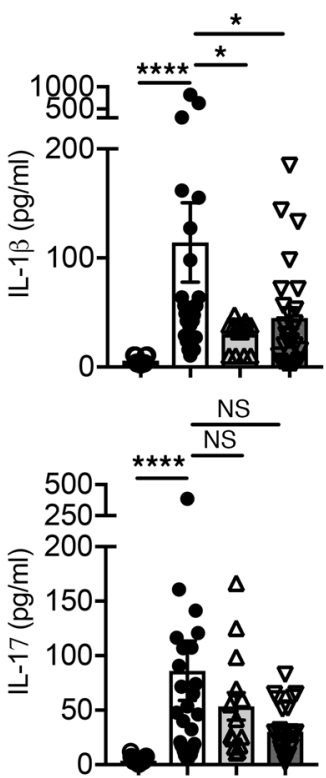

B

$\rightarrow M^{+N} v^{+N 726 A}(n=8)$

.অ. MefV V726AN726A $(n=9)$

-A- MefVV726AV726A $\times \operatorname{Tnf}^{\prime-}(n=6)$

-7. MefiV726AV726A $\times$ Tnfr $^{-/-} \times$Tnfr2 $^{-/-}(n=16)$

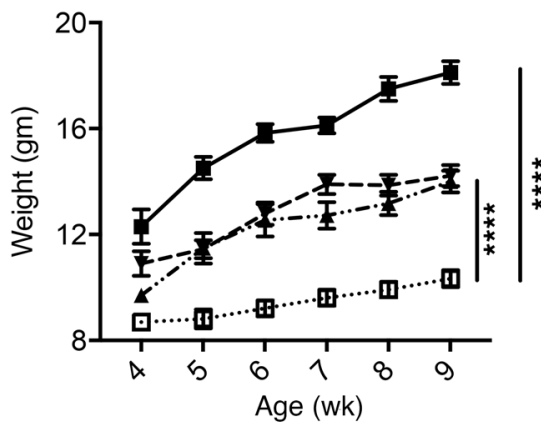

- MefvV726av726a

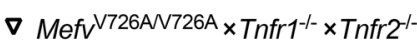

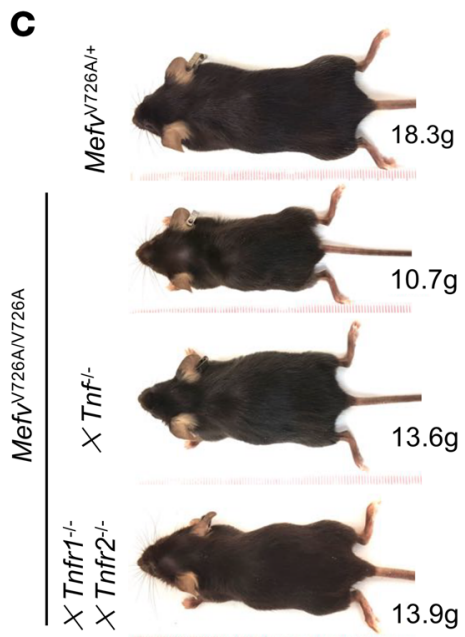

$13.9 \mathrm{~g}$
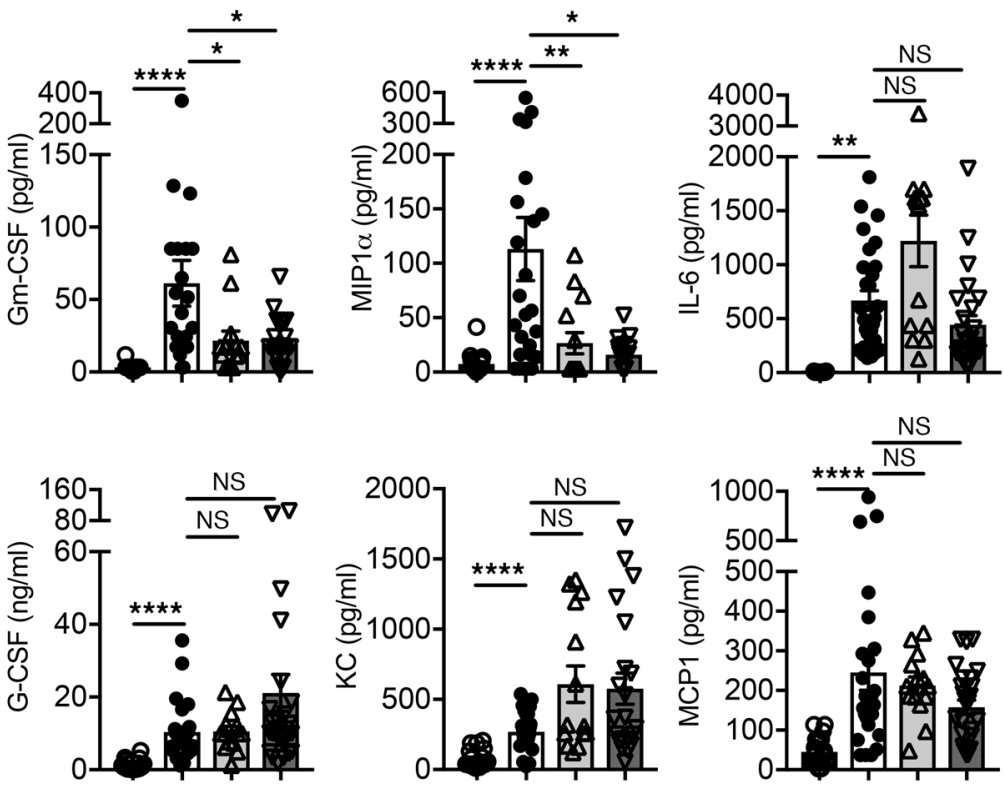

Figure 3. TNF signaling promotes runting and systemic inflammation in Mefv ${ }^{\mathrm{v} 726 \mathrm{~A} / \mathrm{V726A}}$ mice. (A) Level of TNF in serum of indicated mice at 8 to 10 weeks of age. (B) Body weights of indicated number of female mice and (C) representative whole-body image of mice at 8 weeks of age. (D) Cytokine levels in serum samples. (A, B, D) Data are presented as mean \pm SEM with (A and D) $n=14-30$ for each genotype. ${ }^{*} P<0.05$; ${ }^{* *} P<0.01$; ${ }^{* * *} P<0.001$; ${ }^{* * * *} P<$ 0.0001 compared with Mefv $v^{\mathrm{V} 726 \mathrm{~A} / \mathrm{V} 726 \mathrm{~A}}$, Student's $t$ test (A), 2-way ANOVA (B), and Kruskal-Wallis test followed by Dunn's post test (D).

TNFR-deficient donor cells (Mefviv26A/V726A Tnfr/- > WT) (Supplemental Figure 4). These data demonstrate that TNF produced by hematopoietic cells acts on stromal cells to promote neutrophilia in $M e f v^{\mathrm{V} 726 \mathrm{~A} / \mathrm{V726 \textrm {A }} \text { mice. }}$

TNFR1 promotes systemic wasting, anemia, and neutrophilia in $M e f v^{V 726 A / V 726 A}$ mice. TNF is known to signal through both TNFR1 and TNFR2 (44). To assess their relative function in FMF pathologies,

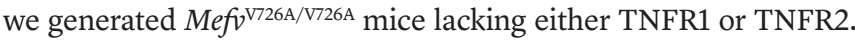
The loss of TNFR1 alone was sufficient to reduce systemic wasting in Mefiv ${ }^{\mathrm{V} 26 \mathrm{~A} / \mathrm{V} 726 \mathrm{~A}}$ mice (Figure 5, A and B). Similar to systemic wasting, parameters of anemia - Hb, HCT, MCV and RDW levels - that were altered in the Mefiv ${ }^{\mathrm{V} 726 \mathrm{~A} / \mathrm{V726A}}$ mice were ameliorated by genetic deletion of TNFR1, while TNFR2 was largely dispensable (Figure 5C). Furthermore, deficiency of TNFR1 prevented neutro- philia, while the loss of TNFR2 had no effect (Figure 6, A and B). Extramedullary granulopoiesis in liver and spleen of Mefv $v^{\mathrm{V} 26 \mathrm{~A} / \mathrm{V} 726 \mathrm{~A}}$ mice too was mediated specifically through TNFR1 (Figure 6C). While splenomegaly was not significantly rescued by loss of TNFR1 (Figure 6D), the number of granulocytes in spleens of Mefv $\mathrm{v}^{\mathrm{V} 26 \mathrm{~A} / \mathrm{N} 726 \mathrm{~A}}$ mice was significantly reduced by specific loss of TNFR1 (Figure 6E). Therefore, these pathogenic effects of TNF in Mefvi mice are mediated specifically through TNFR1 signaling.

TNFR2 signaling is protective against colitis and arthritis in Mefiv ${ }^{V 26 A / V 726 A}$ mice. Serosal inflammation, including inflammation in the colon and joints, has been observed in both FMF patients (50) and the murine model of FMF (5). We have previously shown that IL-1 $\beta$ protects against serosal tissue inflammation in Mefv $v^{\mathrm{V} 26 \mathrm{~A} / \mathrm{V} 726 \mathrm{~A}}$ mice (10). Since anti-TNF therapies have been used 
Table 1. Modulation in anemia and blood cellular composition by TNF and TNFR signaling in Mefv $v^{\mathrm{V726A} / \mathrm{V726A}}$ mice

\begin{tabular}{|c|c|c|c|c|}
\hline & $\mathrm{Mefv}^{+/ N 726 A}$ & Mefv ${ }^{1726 A / V 726 A}$ & $M e f v^{V 726 A / V 726 A} \times \operatorname{Tnf}^{-1-}$ & 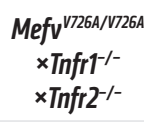 \\
\hline$n$ & 39 & 35 & 12 & 39 \\
\hline WBC $\left(\times 10^{6}\right)$ & $12.04 \pm 0.51^{A}$ & $13.78 \pm 0.73$ & $10.68 \pm 1.11^{A}$ & $13.3 \pm 1.39^{A}$ \\
\hline Neutrophil (\%) & $21.87 \pm 1.05^{\circ}$ & $74.61 \pm 1.40$ & $43.89 \pm 5.96^{c}$ & $35.99 \pm 1.97^{\circ}$ \\
\hline Lymphocyte (\%) & $69.92 \pm 1.06^{\circ}$ & $20.54 \pm 1.32$ & $48.55 \pm 5.31^{\complement}$ & $56.84 \pm 1.87^{\circ}$ \\
\hline Monocyte (\%) & $6.72 \pm 0.23^{\circ}$ & $2.36 \pm 0.13$ & $4.72 \pm 0.55^{c}$ & $5.04 \pm 0.29^{\circ}$ \\
\hline $\mathrm{RBC}\left(\times 10^{6}\right)$ & $8.54 \pm 0.10^{\circ}$ & $7.59 \pm 0.16$ & $7.05 \pm 0.43$ & $7.64 \pm 0.26$ \\
\hline $\mathrm{Hb}(\mathrm{g} / \mathrm{dl})$ & $13.03 \pm 0.12^{0}$ & $8.06 \pm 0.14$ & $8.55 \pm 0.42$ & $9.26 \pm 0.28^{B}$ \\
\hline MCV (fl) & $44.06 \pm 0.25^{\circ}$ & $30.92 \pm 0.53$ & $35.57 \pm 0.88^{A}$ & $37.1 \pm 0.87^{0}$ \\
\hline RDW (\%) & $13.28 \pm 0.11^{0}$ & $29.45 \pm 0.81$ & $24.61 \pm 0.97^{\AA}$ & $21.69 \pm 0.47^{\circ}$ \\
\hline HCT & $37.96 \pm 0.45^{\circ}$ & $23.36 \pm 0.48$ & $24.83 \pm 0.87$ & $27.79 \pm 0.82^{\mathrm{B}}$ \\
\hline
\end{tabular}

Complete blood count analysis for proportion of immune cells and features of anemia, including $\mathrm{Hb}$, $\mathrm{HCT}, \mathrm{MCV}$, and RDW levels in the blood of indicated mice. $n$, number of individual mice analyzed. ${ }^{A} P<0.05$; ${ }^{\mathrm{B} P}<0.1$; ${ }^{\mathrm{C} P}<0.01$; ${ }^{\mathrm{D}} P<0.0001$ compared with MefV ${ }^{\mathrm{V} 726 \mathrm{~A} / \mathrm{V726A}}, 1$-way ANOVA followed by Fischer's LSD test or Kruskal-Wallis followed by Dunn's post test.

in the treatment of inflammatory disorders, including colitis and arthritis, we theorized that TNF signaling would be particularly important in colon and joint inflammation. The colon tissue was assessed for histological perturbations, and colons from $M e f v^{\mathrm{V} 726 \mathrm{~A} / \mathrm{V} 26 \mathrm{~A}}$ mice exhibited substantial inflammation characterized by immune cell infiltration in both the mucosa and submucosa. While the genetic loss of TNF or TNFR1 provided significant protection against colonic inflammation, the absence of TNFR2 exacerbated inflammation in the colons of Mefiv ${ }^{\mathrm{V} 726 \mathrm{~A} / \mathrm{V} 26 \mathrm{~A}}$ mice (Figure 7, A and B). Further, loss of TNFR2 also negated the protection provided by loss of TNFR1, and mice with concomitant loss of both TNFR1 and TNFR2 displayed inflammation comparable to that of Mefv v726A/V726A mice (Figure 7, A and B).

In addition to colitis, Mefiv ${ }^{\mathrm{V} 26 \mathrm{~A} / \mathrm{V} 726 \mathrm{~A}}$ mice exhibited joint inflammation that was visibly discernible in the hind limbs of the mice (Figure 7C). Ankle inflammation (in the form of joint swelling) was observed in about $50 \%$ of $M e f v^{\mathrm{V} 726 \mathrm{~A} / \mathrm{V} 726 \mathrm{~A}}$ mice, $63 \%$ of $M e f v^{\mathrm{V} 226 \mathrm{~A} / \mathrm{V} 726 \mathrm{~A}}$ Tnfr2 $2^{--}$, and $53 \%$ of Mefv ${ }^{\mathrm{V} 26 \mathrm{~A} / \mathrm{V} 726 \mathrm{~A}} \mathrm{Tnfrr}^{-/} \mathrm{Tnfr}^{-/-}$mice (Figure 7C). Genetic deletion of TNF or TNFR1 was protective against the joint pathology, with none of the TNF- or TNFR1-deficient $M e f v^{v 726 \mathrm{~A} / \mathrm{V} 26 \mathrm{~A}}$ mice exhibiting joint inflammation (Figure 7C). These data demonstrate that TNF/TNFR1 signaling promotes colitis and joint inflammation in the FMF model, while TNFR2 signaling is protective. Further, the protection provided by absence of TNFR1 was lost with simultaneous deletion of TNFR2 (Figure 7). Therefore, TNRF1 and TNFR2 function distinctly to alter serosal and systemic inflammation in Mefv $v^{\mathrm{V} 26 \mathrm{~A} / \mathrm{V} 726 \mathrm{~A}}$ mice. Given that the loss of TNFR1 does not protect Mefiv ${ }^{\mathrm{V} 26 \mathrm{~A} / \mathrm{V} 726 \mathrm{~A}}$ mice lacking TNFR2, the protection conferred by TNFR 2 signaling is unlikely to be mediated through sequestration of TNF or inhibition of the pathogenic TNFR1-mediated signal.

One of the major antiinflammatory roles ascribed to TNFR2 signaling includes stability of Tregs $(51,52)$. TNFR2 agonists have been used as a strategy to boost Treg response (53). We therefore assessed whether loss of TNFR2 affected the proportion of Tregs in Mefv $v^{\mathrm{v} 26 \mathrm{~A} / \mathrm{V} 726 \mathrm{~A}}$ mice. The proportion of Tregs was significantly increased in both the spleens and popliteal LNs (pLN) of $M e f v^{\mathrm{V} 26 \mathrm{~A} / \mathrm{V} 726 \mathrm{~A}}$ mice and was reduced with simultaneous deletion of both TNFR1 and TNFR2 (Supplemental Figure 5). The loss of TNFR2 alone, however, did not result in a similar decrease in the proportion of Tregs (Supplemental Figure 5). Within the pLN, the proportion of Tregs was instead significantly enhanced in the absence of TNFR2 (Supplemental Figure 5). Therefore, the proportion of Tregs correlated with the extent of inflammation and was not intrinsically regulated by TNFR2. These data preclude the loss of Tregs as the mechanism for increased colitis and joint inflammation in $M e f v^{7726 \mathrm{~A} / \mathrm{V} 26 \mathrm{~A}}$ mice lacking TNFR2.

\section{Discussion}

In this manuscript, we demonstrate that the TNF/TNFR axis plays a critical role in pyrin inflammasome activation in response to a canonical stimulus and in a gain-of-function mutation model. TNF signaling is critical to pyrin expression in response to inflammatory triggers in cells of myeloid lineage. TNF mRNA is detectable during macrophage differentiation (54), and mTNF is expressed basally in differentiated macrophages (55). Therefore, the role of the TNF/TNFR axis in pyrin expression in macrophages could be a result of both basal and induced TNF signaling. The TNF/TNFR axis further promoted the inflammatory disorder in Mefivi ${ }^{\mathrm{V} 26 \mathrm{~A} / \mathrm{V} 726 \mathrm{~A}}$ mice that exhibit aberrant pyrin inflammasome activation (10). We have previously shown that TNF production in Mefv $v^{\mathrm{V} 26 \mathrm{~A} / \mathrm{V726A}}$ mice was abrogated in mice lacking the ASC/Casp1/IL-1 $\beta$ axis (10). The data presented in this manuscript propose a feedback loop for the TNF/pyrin inflammasome axis, with TNF signaling and inflammasome activation synergistically amplifying the inflammatory response. This also suggests that pyrin inflammasome-mediated IL-1 $\beta$ promotes TNF production to modulate certain features of FMF pathology (Supplemental Figure 6). The intersection of TNF with IL-1 cytokines has also been observed in other autoinflammatory models, including neutrophilic dermatosis (56) and skin inflammation (57-59). A recent study reported that TNF promotes expression of inflammasome components and inflammatory disease in a mouse model of NLRP3 inflammasomopathy $(60,61)$. However, similarly to what was shown in a prior report (62), we found no role for TNF in promoting NLRP3 expression or inflammasome activation in BMDMs. TNF could, however, affect expression and activation of NLRP3 under inflammatory conditions observed in autoinflammatory models.

Further, the pathogenic role of TNF in Mefiv $v^{\mathrm{V} 726 \mathrm{~A} / \mathrm{V} 26 \mathrm{~A}}$ mice is mediated through TNFR1 while TNFR2 signaling is protective against certain pathologies, including arthritis and colitis. TNF/TNFR1 signaling is involved in proinflammatory cytokine production through NF- $\mathrm{kB}$ and MAPK activation and in proapoptotic signaling through the RIPK3/CASP8 axis (63). We have previously shown that, unlike TNFR1 signaling, lack of the 
A

○ Mefv $7726 \mathrm{~A}+$

- Mefv V726av726a

$\triangle$ MefvV726AV726A $\times$ Tnf $^{-1}$

$\nabla$ Mefv ${ }^{\mathrm{V} 26 \mathrm{AN} 726 \mathrm{~A}} \times$ Tnfr $^{-1-} \times \mathrm{Tnfr}^{-1-}$

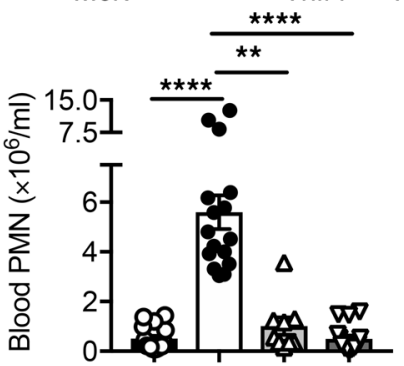

B

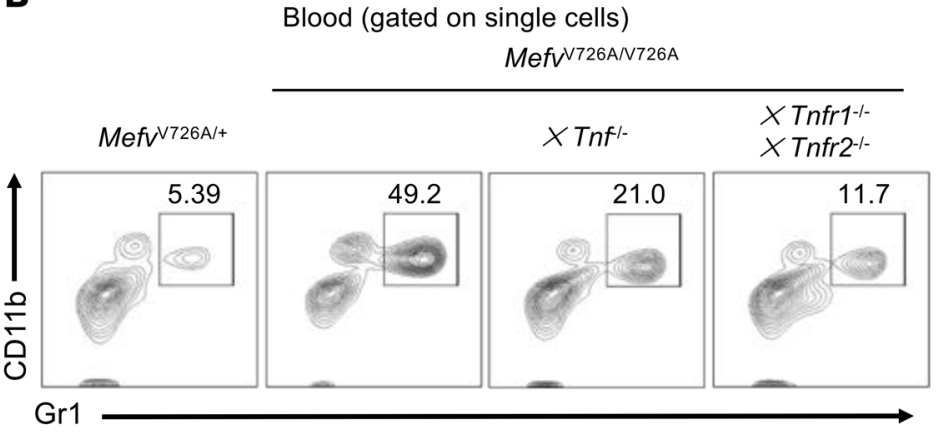

C

Mefv 726 A/V726A
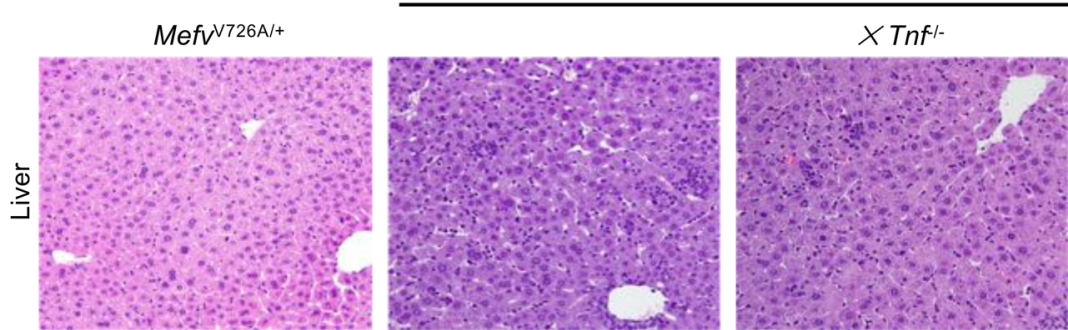

D

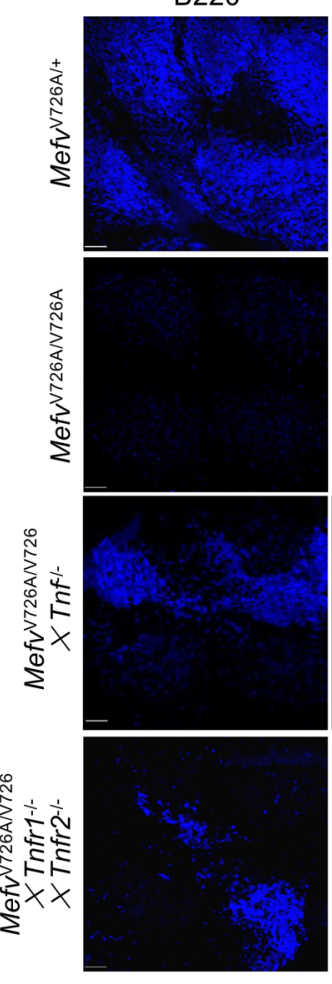

B220
CD3

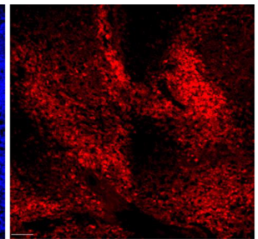

Ly6C
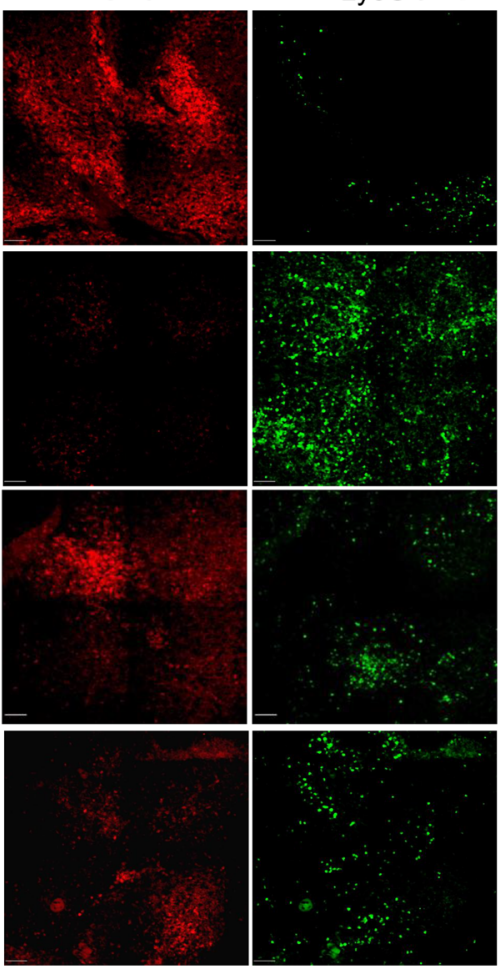

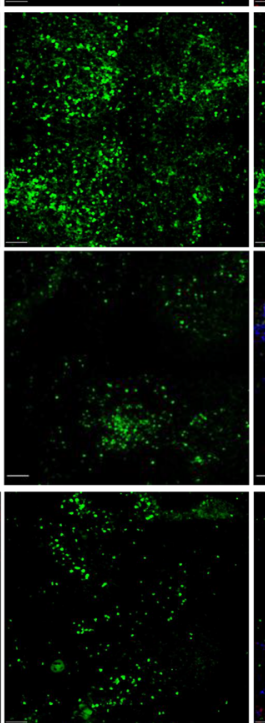

Merge
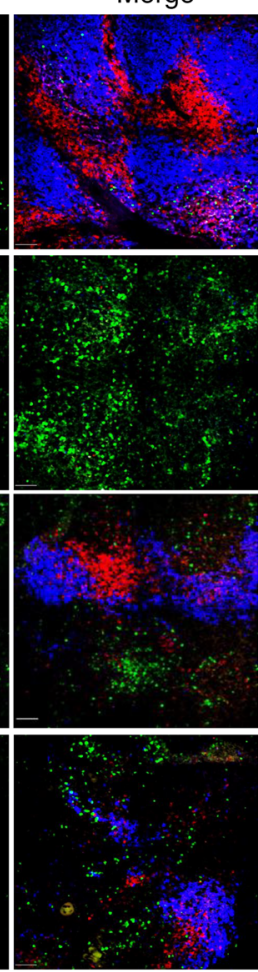

$\times \operatorname{Tnfr} 1^{-1-} \times \operatorname{Tnfr}^{-1-}$

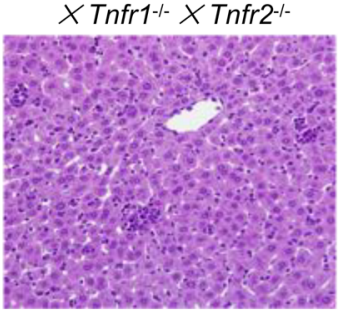

E

- $M_{\text {efv }}^{+N 726 \mathrm{~A}}$

- MefvV726AN726A

$\triangle$ MefvV726AV726A $\times$ Tnf $^{-1-}$

$\nabla$ Mefv ${ }^{V 726 A V 726 A} \times$ Tnfr $^{-1-} \times$ Tnfr $^{-/-}$
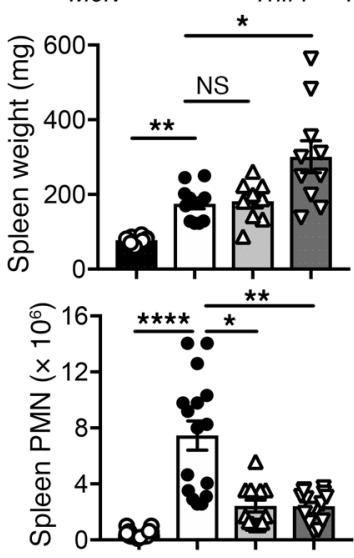

Figure 4. TNF signaling promotes neutrophilia and granulopoiesis in Mefv ${ }^{\text {V726A/V726A }}$ mice. (A) Number of neutrophils (PMN) in blood (/mI) and (B) representative contour plot depicting proportion of PMNs (CD11 $\left.\mathrm{b}^{+} \mathrm{Gr} 1^{+}\right)$in blood of indicated mice. Cells were gated on single cells; the percentage of cells identified as neutrophils is noted on each plot. (C) Representative H\&E-stained sections of liver tissues. Original magnification, $\times 20$. (D) Cellular composition in spleens of Mefv ${ }^{\mathrm{V} 726 \mathrm{~A} / \mathrm{V} 726 \mathrm{~A}}$ mice. B220, CD3, and Ly6C represent B cells, T cells, and monocytes/granulocytes, respectively. Scale bars: $50 \mu M$. (E) Weight and total number of granulocytes in the spleens of indicated mice. (A and $\mathbf{E}$ ) Data are presented as mean \pm SEM with $n=8-16$ for each genotype. ${ }^{*} P<0.05$; ${ }^{* *} P<0.01 ;{ }^{* * *} P<0.0001$ compared with Mefv ${ }^{\mathrm{V} 26 \mathrm{~A} / \mathrm{V726A}}$ mice, using Kruskal-Wallis test followed by Dunn's post test. 
A

- Mefv $726 \mathrm{~A}+(n=12)$

- MefvV726AV726A $(n=9)$

- MefvV726AV726A $\times$ Tnfr $^{-1-}(n=5)$

a MefV V726AV726A $\times$ Tnfr2 $2^{--}(n=6)$

$\nabla$ Mefv $2726 \mathrm{AN} 726 \mathrm{~A} \times$ Tnfr $^{-1-} \times$ Tnfr2 $^{-1-}(n=18)$

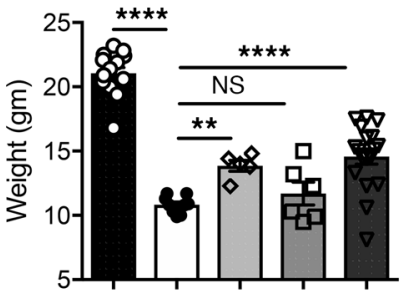

8 weeks (Age)
B

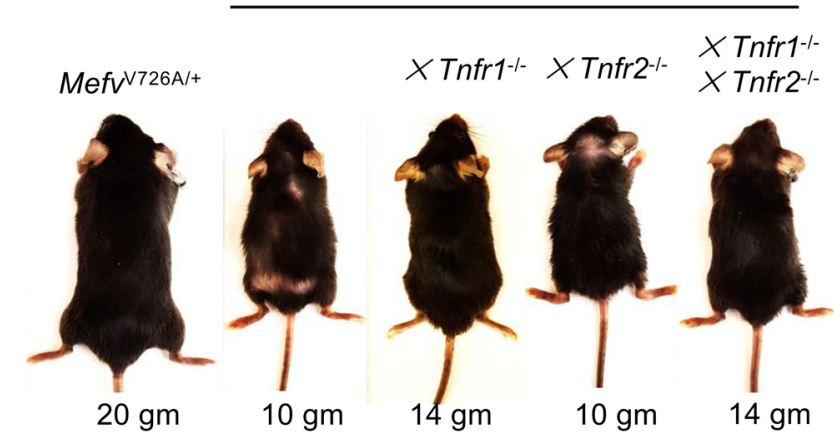

C

- Mefv $+N 726 A$

- MefiV726AV726A

- MefV V726AN726A $\times$ Tnfr1 $1^{-/-}$

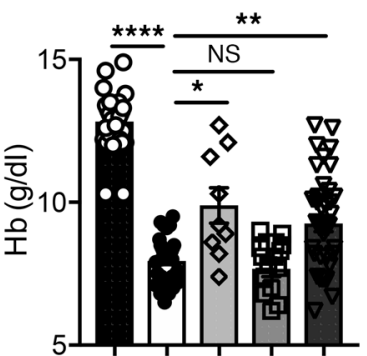

ㅁ Mefv V726AN726A $\times$ Tnfr2 $2^{-/-}$

$\nabla$ Mefv V726AV726A $\times$ Tnfr1 $1^{-/-} \times T_{n f r} 2^{-/-}$
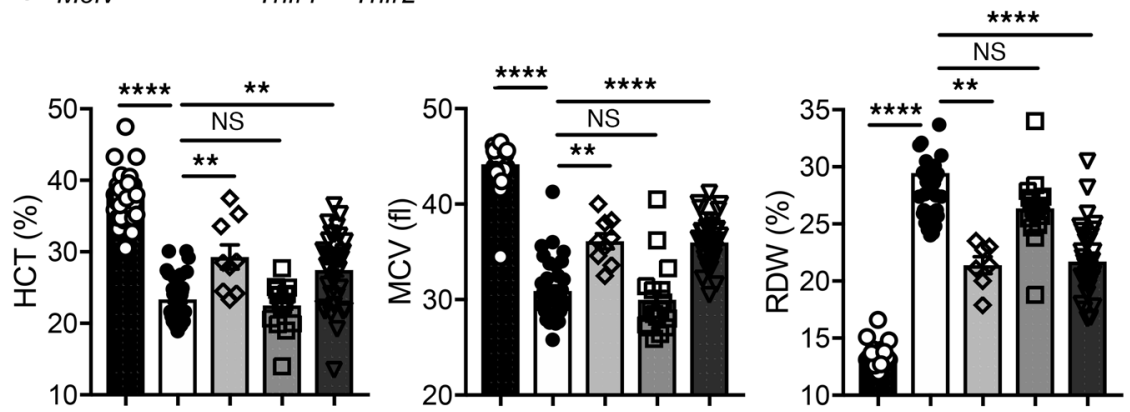

Figure 5. TNFR1 signaling promotes runting and anemia in Mefv ${ }^{\mathrm{V726A} / \mathrm{V726A}}$ mice. (A) Body weights of indicated numbers of female mice and (B) representative whole-body images of mice at 8 weeks of age. (C) Features of anemia, including Hb, HCT, MCV, and RDW levels in the blood of indicated mice. $n=9-39$ per genotype. (A and $\mathbf{C}$ ) Data are presented as mean $\pm \mathrm{SEM}$. ${ }^{*} P<0.05 ;{ }^{* *} P<0.01$; ${ }^{* * *} P<0.0001$ compared with Mefv ${ }^{\mathrm{V} 26 \mathrm{~A} / \mathrm{V} 726 \mathrm{~A}}$ using (A and $\left.\mathbf{C}\right) 1-$ way ANOVA or Kruskal-Wallis followed by Fisher's LSD or Dunn's post test.

RIPK3/CASP8 axis does not provide any protection against FMF disease, indicating that TNFR1-mediated cell death is not relevant to disease progression in this model (10). TNF-mediated inflammation, therefore, might be the critical pathogenic function mediated by TNFR1 signaling. It was further surprising and interesting that the loss of TNFR2 increases disease severity in colon and joints without exacerbating systemic disease. This suggests that the systemic disease features, including weight loss and neutrophilia, are dominantly modulated by TNFR1 signaling and that the status of TNFR2 expression has no significant effect. Based on these observations, it is clear that the overall disease outcome depends on the significance and balance of signaling via TNFR1 or TNFR2. TNF blockade is being used as a therapy for treatment of inflammation-associated amyloidosis and proteinuria in patients with FMF that do not respond to colchicine (23-25, 64, 65). Distinct features of the disease, including arthritis $(21,61)$ and abdominal inflammation $(21)$, have been treated by specific targeting of sTNF, which has a higher affinity for TNFR1 while leaving mTNF signaling intact $(22,66)$. Selective targeting of TNF to restrict TNFR1 inflammatory programming while keeping the antiinflammatory function of TNFR2 intact could be particularly beneficial for treatment of specific ailments associated with FMF and needs to be explored further as a therapeutic strategy.
While the loss of TNF/TNFR signaling provided substantial protection against all disease characteristics, it was particularly effective against neutrophilia. We further demonstrated that TNF produced by hematopoietic cells is a critical driver of neutrophilia in Mefv $v^{\mathrm{V} 726 \mathrm{~A} / \mathrm{V} 726 \mathrm{~A}}$ mice. Granulocyte-derived TNF has been recently shown to promote vascular remodeling and hematopoietic recovery during BM transplantation (67). The specific role of TNFR1 signaling in neutrophilia in Mefiv $v^{\mathrm{V} 26 \mathrm{~A} / \mathrm{V} 726 \mathrm{~A}}$ mice is consistent with previous studies that show that TNFR1, but not TNFR2, synergizes with GM-CSF to promote granulocyte differentiation $(49,68)$. Additionally, it was interesting that neutrophilia in $M e f v^{\mathrm{V} 726 \mathrm{~A} / \mathrm{V} 726 \mathrm{~A}}$ mice lacking TNF signaling was reduced despite significant levels of neutrophilia-promoting mediators, such as G-CSF, KC, and IL-17, in these mice (Figure 3D). However, TNF can modulate hematopoiesis (49, $68)$, expression of adhesion molecules $(69,70)$, and neutrophil chemotaxis and apoptosis $(71,72)$, and it is likely that neutrophilia in FMF mice is affected by these functions of TNF signaling.

Distinct, synergistic, and opposing functions of TNFR1 and TNFR2 have been demonstrated in various models, including sepsis (73), TNF-induced cutaneous inflammation $(74,75)$, skin necrosis (76), collagen-induced arthritis (77), and experimental autoimmune encephalomyelitis (EAE) (78). TNF-overexpressing mice exhibit arthritis and colitis that is mediated by TNFR1, but protected by TNFR2-mediated signaling (79). We observed that 
A

- Mefvi $^{+N 726 A}$

- MefVV726AV726A

$\diamond$ MefvV726AV726A $\times$ Tnfr1 $1-$

- Mefv V726AV726A $\times$ Tnfr2 $2^{-/-}$

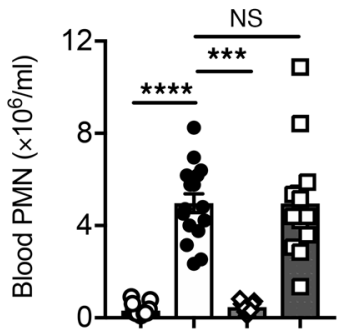

B

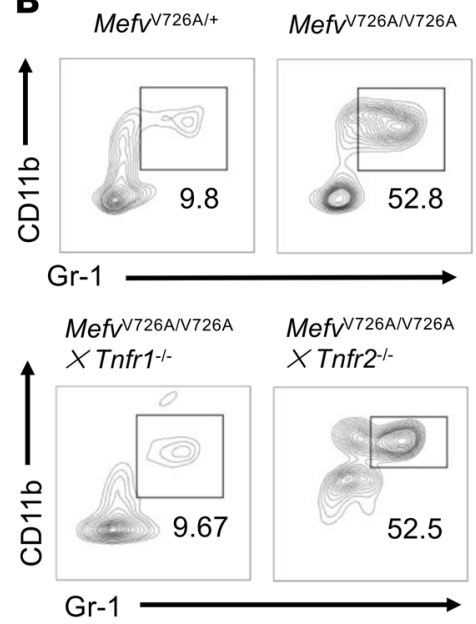

C
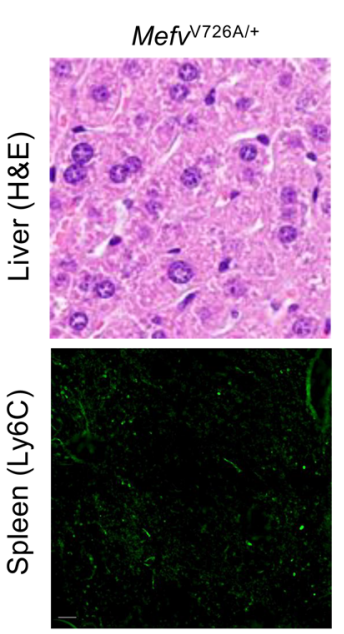

D

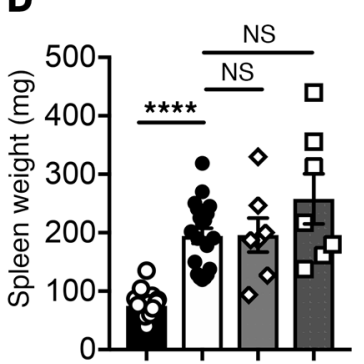

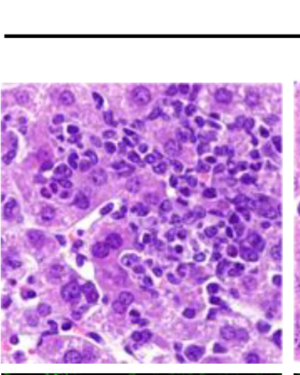

Mefv V726A/V726A
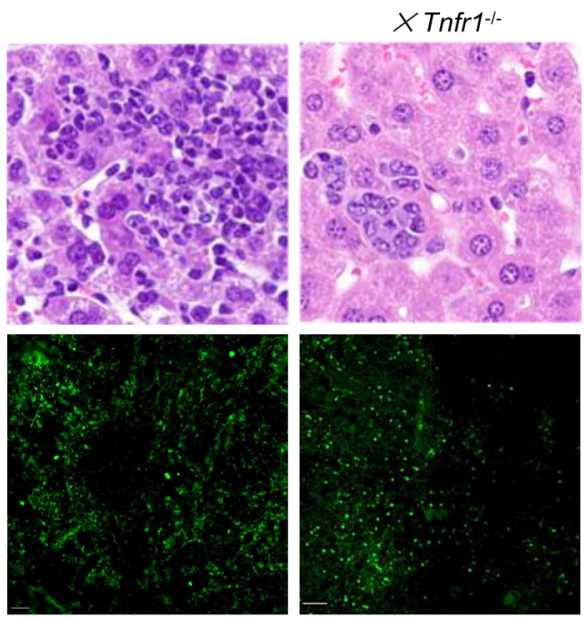

E

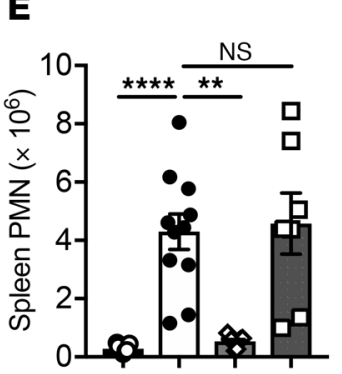

- $\mathrm{Mefv}^{+N 726 \mathrm{~A}}$

- MefvV726AN726A

- MefvV726AV726A $\times$ Tnfr1 ${ }^{-1-}$

口 MefVV726AV726A $\times$ Tnfr2 ${ }^{-/-}$

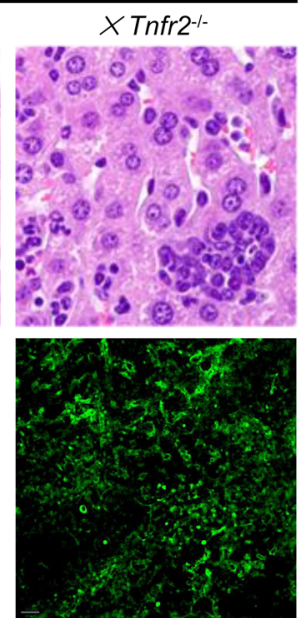

Figure 6. TNFR1 signaling promotes neutrophilia and granulopoiesis in Mefv ${ }^{\mathrm{v726A} / \mathrm{V726A}}$ mice. (A) Number of neutrophils (PMN) in blood $(/ \mathrm{ml})$ and $(\mathbf{B})$ representative dot plot depicting proportion of PMNs (CD11b+Cr1+) in blood of indicated mice. Cells were gated on single cells; percentage of cells identified as neutrophils is noted on each plot. (C) Representative H\&E-stained sections of liver tissues and immunofluorescence for myeloid cells (Ly6C) in the spleen. Scale bars: $50 \mu \mathrm{M}$. Original magnification, $\times 40$. (D) Weight and (E) total number of granulocytes in the spleens of indicated mice. (A, D, E) $n=6-16$ per genotype. ${ }^{* *} P<0.01$; ${ }^{* *} P<$ $0.01 ;{ }^{* * *} P<0.0001$ compared with Mefv $v^{\mathrm{V} 726 \mathrm{~A} / \mathrm{V} 726 \mathrm{~A}}$ by Kruskal-Wallis followed by Dunn's post test. not negatively regulate pyrin inflammasome activation (Deepika Sharma, unpublished observations), disproving inhibition of innate inflammasome response as the possible mechanism for increased mucosal inflammation in Mefiv ${ }^{\text {v726A/V726A }}$ mice lacking TNFR2.

The protective role of TNFR2 in arthritis and colitis in Mefiv ${ }^{\mathrm{v} 26 \mathrm{~A} / \mathrm{V} 726 \mathrm{~A}}$ mice, however, was surprising, as loss of TNF does not phenocopy the simultaneous loss of TNFR1 and TNFR2. We propose that TNFR2 exhibits its protective function through interaction with ligands other than TNF. Lymphotoxin is known to signal through TNFRs (1 and 2) $(80,81)$, and even a TNF- and lymphotoxin-independent role for TNFR2 signaling has been previously reported (82). Similarly, TNFindependent and antagonistic functions of the 2 TNF receptors have been previously reported in retinal ischemia (83). Specific targeting of TNFR2 is being investigated as a therapeutic strategy for treatment of type 1 diabetes (53), graft -versushost disease (84), and cancer (85). Therefore, delving into the precise effect of specific TNF signaling (through TNFR1 or TNFR2) in various autoinflammatory disorders is an important area of research.

Overall, our data demonstrate a critical role for TNF in FMF pathologies and describe the protective and pathogenic features of TNF/TNFR signaling. Our data further point to selective TNF targeting for distinct inflammatory features in autoinflammatory disorders such as TRAPS and inflammasomopathies FMF.

\section{Methods}

Mice. Mefiv $v^{\mathrm{V} 726 \mathrm{~A} /+}$ and $M e f v^{\mathrm{V} 726 \mathrm{~A} / \mathrm{V} 726 \mathrm{~A}}$ mice have been previously described (5) and were provided by Dan Kastner (NIH, Bethesda, Maryland). Mefv $v^{\mathrm{V} 26 \mathrm{~A} /+}$ mice were bred with Tnf ${ }^{\prime-}$ (86) and Tnfr1 ${ }^{-/-}$Tnfr. $2^{-/}$ (38) mice to generate $M e f v^{\mathrm{V} 726 \mathrm{~A} / \mathrm{V} 726 \mathrm{~A}}$ mice lacking each of these components.

the absence of TNFR2 did not promote organ-specific inflammation through loss of Tregs. Further, the arthritis in TNFoverexpressing mice is independent of the adaptive immune system (79). This suggests that the protective role of TNFR2 in the colon and joint inflammation in Mefv $v^{\mathrm{V} 726 \mathrm{~A} / \mathrm{V} 726 \mathrm{~A}}$ mice is independent of TNF signaling and Treg stability. TNFR2 additionally did
Cellular processing and analysis. Mice were monitored weekly for weight gain starting from 3 to 4 weeks of age and euthanized at 8 to 12 weeks of age for systemic analysis. Blood was collected through a cardiac puncture, and $50 \mu \mathrm{l}$ was added to anticoagulant EDTA for cellular $40 \mu \mathrm{m}$ filter to obtain a single-cell suspension. Both blood and spleen analysis. The spleen and LNs were homogenized and passed through a 
A

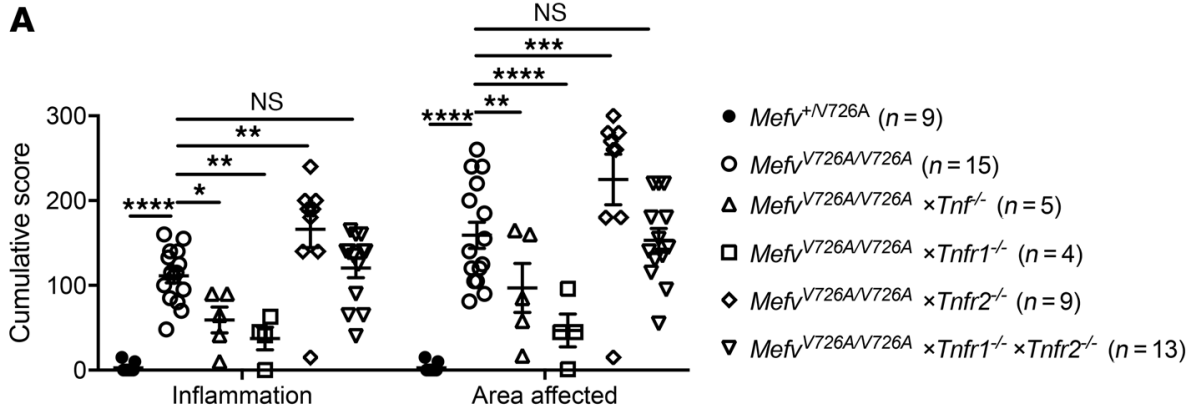

B

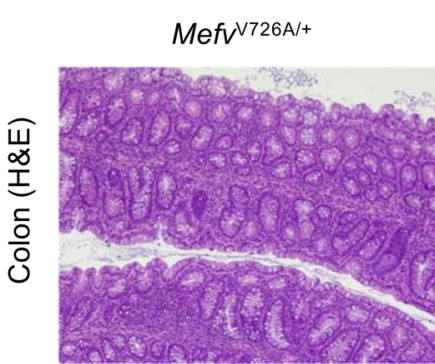

Mefiv726A/V726A
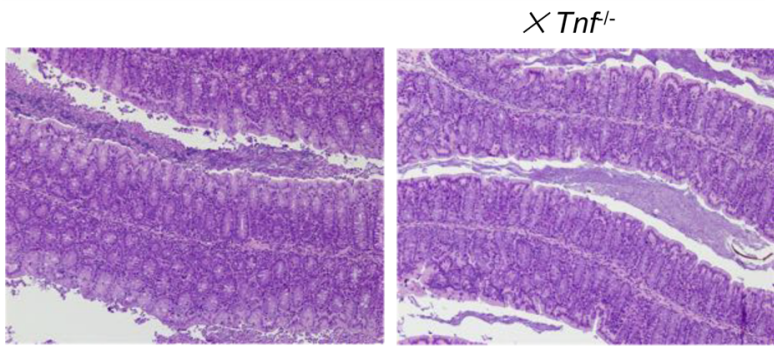

Mefvi726A/N726A

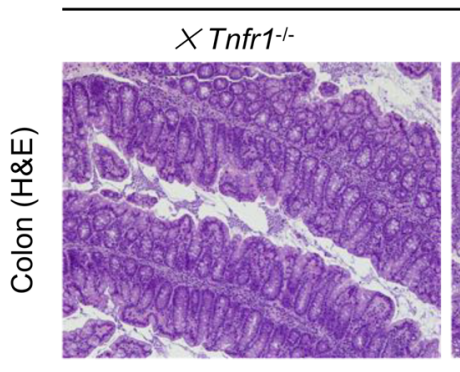

$X$ Tnfr- $^{-1-}$

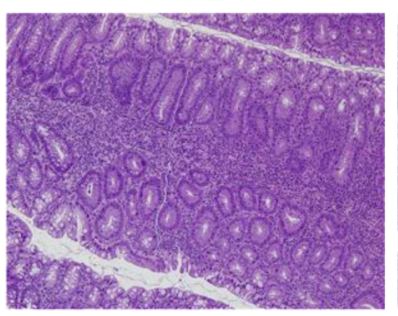

Mefiv726A/V726A

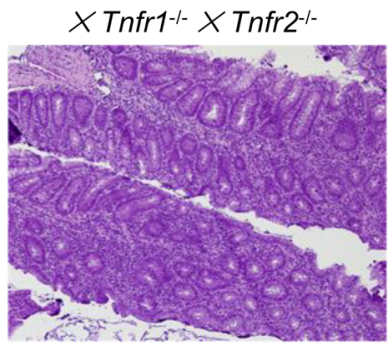

C

Figure 7. Serosal inflammation in Mefv $v^{\mathrm{V} 726 \mathrm{~A} / \mathrm{V} 726 \mathrm{~A}}$ mice is distinctly mediated by TNFR signaling. (A) Histological analysis of colon tissue in mice. (B) Representative images of $\mathrm{H} \& \mathrm{E}$ staining of proximal colon. Original magnification, $\times 10$. (C) Photograph of mice highlighting ankle joint inflammation in strains of $M e f v^{\mathrm{V} 726 \mathrm{~A} / \mathrm{V} 726 \mathrm{~A}}$ mice. The numbers below each image represent the proportion of mice in which joint inflammation was visibly discernible. ${ }^{*} P<0.05$; ${ }^{* *} P<0.01$; ${ }^{* * *} P$ $<0.001 ;{ }^{* * *} P<0.0001$ compared with Mefv V726A/V726A, 2-way ANOVA followed by Fischer's LSD test.

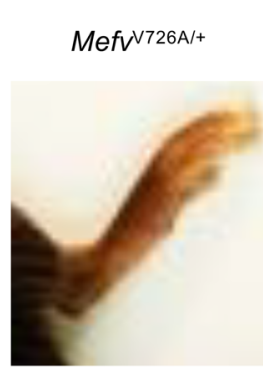

$0 / 30$

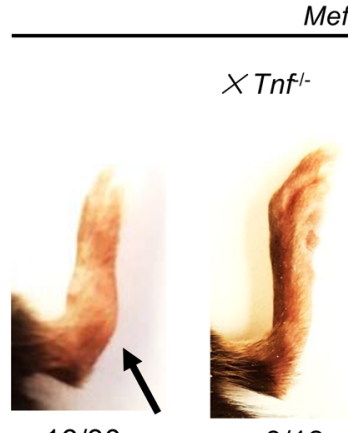

$16 / 30$

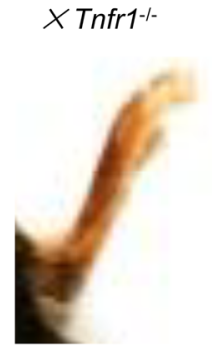

$0 / 9$

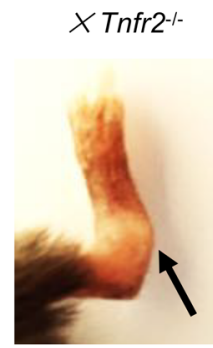

$7 / 11$ $\times$ Tnfr1-1- $^{-1}$
$\times$ Tnfr $^{-1-}$

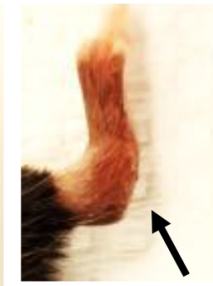

$18 / 32$ were subjected to RBC lysis and washed in complete media. Cells obtained from blood, spleen, and LNs were fixed with 2\% paraformaldehyde (Affymetrix) and stained for cellular analysis. For Treg staining, cells were fixed in nuclear stain fixative (Tonbo Biosciences) per the manufacturer's recommendation.

Flow cytometry. The following antibodies were used for cell staining: CD11b (clone M1/70), CD19 (clone 6D5), CD3 (clone 17A2), Gr-1 (clone RB6-8C5), CD4 (clone RM4-4), and Foxp3 (clone FJK-16) (Thermo Fisher Scientific). Cells were stained, run on an LSRII flow cytometer (BD Biosciences), and analyzed with FlowJo software, version 10.2 (FlowJo LLC).

Histology and microscopy analysis. Liver and colon were fixed in $10 \%$ formalin, embedded in paraffin, sectioned, and stained with
H\&E. A board-certified pathologist analyzed the H\&E sections for the presence of inflammation and signs of tissue damage in a blinded manner. Inflammation was categorized as follows: normal, small number of lymphocytes and plasma cells in lamina propria; minimal, small, focal mixed inflammatory infiltrates, including neutrophils and macrophages, limited to lamina propria; mild, multifocal mixed inflammation often extending into submucosa; moderate, large multifocal lesions with mixed immune infiltrates extending into mucosa and submucosa; marked, extensive mixed inflammation, with edema, small erosions/ ulcers, and small areas of transmural inflammation; and severe, diffuse transmural inflammation with multiple ulcers. These categories were scored as follows: 0 , normal; 15 , minimal; 40 , mild; 60 , moder- 
ate; 80, marked; and 10, severe. Inflammation scores across proximal, middle, and distal regions of the colon were added to get a cumulative inflammation score.

Area affected was graded as follows: normal, rare or inconspicuous lesions; minimal, less that $5 \%$ of area affected; mild, multifocal or small, focal, or widely separated, but conspicuous lesions with $5 \%$ to $10 \%$ involvement; moderate, multifocal, prominent lesions with $10 \%$ to $50 \%$ involvement; marked, coalescing to extensive lesions or areas of inflammation with some loss of structure with $50 \%$ to $90 \%$ involvement; and severe, diffuse lesion with effacement of normal structure and over $90 \%$ involvement. These categories were scored as 0 , normal; 1 , minimal; 15 , mild; 25 , moderate; 40 , marked; and 80 , severe. Area affected or extent of inflammation scores across proximal, middle, and distal regions of the colon were added to get a cumulative area affected score.

Immunofluorescence. Splenic tissue was fixed in 2\% paraformaldehyde for 24 hours followed by cryoprotection with $20 \%$ sucrose before embedding in OCT medium. Cryosections that were $10 \mu \mathrm{m}$ thick were blocked by incubation in TBS containing 2\% BSA and 5\% normal goat serum for 30 minutes prior to incubation with AF488-conjugated anti-B220 (BioLegend; clone RA3-6B2), AF594-conjugated anti-Ly6C (BioLegend; clone HK1.4), and AF647-conjugated anti-CD3 (BioLegend; clone 17A2) overnight at $4^{\circ} \mathrm{C}$. Slides were washed for 15 minutes in TBS prior to mounting with ProLong Gold Diamond Antifade Mountant (Thermo Fisher Scientific). Fluorescent images were acquired using an inverted TiE microscope (Nikon) equipped with a $0.75 \mathrm{NA}$ $\times 20$ objective and an iXon Ultra EMCCD camera and analyzed using NIS Elements software (Nikon Instruments).

Toxin preparation. C. difficile toxin was prepared as previously described (87). Briefly, C. difficile strain r20291 ( $\mathrm{AB}^{-}$and $\left.\mathrm{AB}^{+}\right)$was cultured in tryptone-yeast extract media for 24 hours in an anaerobic chamber at $37^{\circ} \mathrm{C}$. Cultures were diluted to an OD that corresponds to $2 \times 10^{7}$ $\mathrm{CFU} / \mathrm{ml}$ and spun down; the supernatant was sterilized using $0.22 \mu \mathrm{M}$ filters. Supernatant prepared from toxin-negative (control) and toxinpositive strain was used to stimulate BMDMs at a 1:5 dilution.

Purified TcdB was obtained from List Biological Laboratories (catalog 155) and used at final concentration of $0.5 \mu \mathrm{g} / \mathrm{ml}$, as previously described (7).

Cell culture and stimulation. Monocytes were obtained by culturing cells from BM in DMEM media (Thermo Fisher) supplemented with 30\% media conditioned by L929 fibroblasts, 10\% FBS, nonessential amino acids (NEAAs), and penicillin-streptomycin for 3 days. Nonadherent monocytes were collected, counted, and plated at a density of $1 \times 10^{6}$ cells per $\mathrm{ml}$ for stimulation. Cells were stimulated with $200 \mathrm{ng} / \mathrm{ml}$ LPS (InvivoGen) for 24 hours. BMDMs were generated as previously described (62). For pyrin activation, cells were resuspended in opti-MEM (Thermo Fisher) media and stimulated with $C$. difficile supernatant $\left(\mathrm{AB}^{-}\right.$and $\left.\mathrm{AB}^{+}\right)$for 16 hours. For NLRP3 activation, cells were primed with LPS $(200 \mathrm{ng} / \mathrm{ml})$ for 4 hours followed by ATP $(5 \mathrm{mM})$, nigericin $(1 \mu \mathrm{M})$, and silica $(250 \mu \mathrm{g} / \mathrm{ml})$ for 30 minutes, 2 hours, and 12 hours, respectively. For NLRC 4 activation, cells were stimulated with log-phase Salmonella and Pseudomonas at an MOI of 1 for 4 hours. For AIM2 activation, cells were primed with LPS (200 ng/ml) for 4 hours, followed by transfection of dsDNA $(2.5 \mu \mathrm{g} / \mathrm{ml})$ using lipofectamine, as previously described (88). At the end of stimulation, $120 \mu \mathrm{l}$ supernatant was removed for ELISA. Cells and supernatants were then lysed with RIPA buffer containing pro- tease inhibitors and phosphatase inhibitors (Millipore) and boiled in SDS sample buffer for Western blot analysis. Caspase-1 activation was assessed by Western blot using the anti-caspase-1 p20 antibody (AG-20B-0042-C100, Adipogen), as previously described (62). See complete unedited blots in the supplemental material.

For analysis of pyrin expression, BMDMs were stimulated with $200 \mathrm{ng} / \mathrm{ml}$ LPS (InvivoGen), 1 $\mu \mathrm{g} / \mathrm{ml}$ Pam3CSK4 (InvivoGen), $5 \mu \mathrm{g} /$ $\mathrm{ml}$ high-molecular weight poly(I:C) (InvivoGen), $50 \mathrm{ng} / \mathrm{ml} \mathrm{TNF}$ (Peprotech), and $500 \mathrm{U} / \mathrm{ml}$ IFN- $\beta$ (PBL assay Science) for indicated periods of time and processed for immunoblot analysis, as previously described (62). The antibodies used for probing included pyrin (catalog ab195975, Abcam), NLRP3 (catalog AG-20B-0014, Adipogen), IL-1 $\beta$ (R\&D Systems), and $\beta$-actin (Cell Signaling Technology), and secondary anti-rabbit, anti-mouse, or anti-goat HRP antibodies (Jackson ImmunoResearch Laboratories).

ELISA. Cytokines in the serum and cell-culture supernatants were measured by ELISA, according to the manufacturers' instructions. The IL-1 $\beta$ and multiplex ELISA kits were obtained from Thermo Fisher and Millipore, respectively.

LDH assay. LDH assay (Promega) was carried out per the manufacturer's instructions. Briefly, $\mathrm{LDH}$ release was assessed in the cell-culture supernatants by incubating with the substrate at $37^{\circ} \mathrm{C}$ for 15 minutes. End-point measurement was conducted by reading the plate at $450 \mathrm{nM}$. A standard curve was similarly generated, and sample spectrometric values were converted to percentage cell death using the curve.

Statistics. All statistical analysis was performed using Prism 6.0 software. Student's $t$ test or 1-way ANOVA was used with Fischer's least significance difference (LSD) or Dunn's post test, as indicated. Two-way ANOVA was used to analyze the kinetics of body weight gain. In most analyses, Mefiv $v^{\mathrm{V} 726 \mathrm{~A} / \mathrm{V} 726 \mathrm{~A}}$ mice were used as a control to demonstrate degree of disease or protection. $P$ values of less than 0.05 were considered significant.

Study approval. Mice were maintained in a specific pathogen-free facility, and animal studies were approved by the St. Jude Children's Research Hospital Committee on the Use and Care of Animals.

\section{Author contributions}

DS and TDK conceptualized the project. DS, AM, and CG executed the experiments. PV carried out histological assessment. DS conducted data analysis. DS and TDK wrote the manuscript. TDK acquired funding and provided resources and overall supervision.

\section{Acknowledgments}

We thank Dan Kastner (NIH) for Mefv $v^{\mathrm{V} 726 \mathrm{~A} /+}$ and Mefv ${ }^{\mathrm{V} 726 \mathrm{~A} / \mathrm{V} 726 \mathrm{~A}}$ mice and Nigel Minton (University of Nottingham, Nottingham, United Kingdom) and William A. Petri Jr. (University of Virginia, Charlottesville, Virginia, USA) for providing the C. difficile strains. We also thank Amanda Burton for technical assistance. This study was supported by grants from the US NIH (AR056296, CA163507, AI101935, and AI124346) and the American Lebanese Syrian Associated Charities (to TDK).

Address correspondence to: Thirumala-Devi Kanneganti, Department of Immunology, St. Jude Children's Research Hospital, MS \#351, 262 Danny Thomas Place, Memphis Tennessee 38105-3678, USA. Phone: 901.595.3634; Email: Thirumala-Devi. Kanneganti@StJude.org. 
1. Chae JJ, Aksentijevich I, Kastner DL. Advances in the understanding of familial Mediterranean fever and possibilities for targeted therapy. $\mathrm{BrJ}$ Haematol. 2009;146(5):467-478.

2. [No authors listed]. Ancient missense mutations in a new member of the RoRet gene family are likely to cause familial Mediterranean fever. The International FMF Consortium. Cell.1997;90(4):797-807.

3. French FMF Consortium. A candidate gene for familial Mediterranean fever. Nat Genet. 1997;17(1):25-31.

4. Papin S, et al. The SPRY domain of Pyrin, mutated in familial Mediterranean fever patients, interacts with inflammasome components and inhibits proIL-1beta processing. Cell Death Differ. 2007;14(8):1457-1466.

5. Chae JJ, et al. Gain-of-function Pyrin mutations induce NLRP3 protein-independent interleukin$1 \beta$ activation and severe autoinflammation in mice. Immunity. 2011;34(5):755-768.

6. Gavrilin MA, et al. Activation of the pyrin inflammasome by intracellular Burkholderia cenocepacia. J Immunol. 2012;188(7):3469-3477.

7. $\mathrm{Xu} \mathrm{H}$, et al. Innate immune sensing of bacterial modifications of Rho GTPases by the Pyrin inflammasome. Nature. 2014;513(7517):237-241.

8. Sharma D, Kanneganti TD. The cell biology of inflammasomes: mechanisms of inflammasome activation and regulation. J Cell Biol. 2016;213(6):617-629.

9. Malik A, Kanneganti TD. Inflammasome activation and assembly at a glance. JCell Sci. 2017;130(23):3955-3963.

10. Sharma D, Sharma BR, Vogel P, Kanneganti TD. IL- $1 \beta$ and caspase- 1 drive autoinflammatory disease independently of IL- $1 \alpha$ or caspase- 8 in a mouse model of familial Mediterranean fever. Am J Pathol. 2017;187(2):236-244.

11. Kanneganti A, et al. GSDMD is critical for autoinflammatory pathology in a mouse model of familial Mediterranean fever. J Exp Med. 2018;215(6):1519-1529.

12. Sharma D, Malik A, Guy CS, Karki R, Vogel P, Kanneganti TD. Pyrin inflammasome regulates tight junction integrity to restrict colitis and tumorigenesis. Gastroenterology. 2018;154(4):948-964.e8.

13. [No authors listed]. Ancient missense mutations in a new member of the RoRet gene family are likely to cause familial Mediterranean fever. The International FMF Consortium. Cell. 1997;90(4):797-807.

14. Matzner Y, et al. Expression of the familial Mediterranean fever gene and activity of the C5a inhibitor in human primary fibroblast cultures. Blood. 2000;96(2):727-731.

15. Centola M, et al. The gene for familial Mediterranean fever, MEFV, is expressed in early leukocyte development and is regulated in response to inflammatory mediators. Blood. 2000;95(10):3223-3231.

16. Schattner A, Gurevitz A, Zemer D, Hahn $\mathrm{T}$. Induced TNF production in vitro as a test for familial Mediterranean fever. QJM. 1996;89(3):205-210.

17. Schattner A, Lachmi M, Livneh A, Pras M, Hahn T. Tumor necrosis factor in familial Mediterranean fever. Am JMed. 1991;90(4):434-438.

18. Baykal Y, Saglam K, Yilmaz MI, Taslipinar A,
Akinci SB, Inal A. Serum sIL-2r, IL-6, IL-10 and TNF-alpha level in familial Mediterranean fever patients. Clin Rheumatol. 2003;22(2):99-101.

19. Drenth JP, van Deuren M, van der Ven-Jongekrijg J, Schalkwijk CG, van der Meer JW. Cytokine activation during attacks of the hyperimmunoglobulinemia D and periodic fever syndrome. Blood. 1995;85(12):3586-3593.

20. Almeida de Jesus A, Goldbach-Mansky R. Monogenic autoinflammatory diseases: concept and clinical manifestations. Clin Immunol. 2013;147(3):155-174.

21. Seyahi E, Ozdogan H, Celik S, Ugurlu S, Yazici H. Treatment options in colchicine resistant familia Mediterranean fever patients: thalidomide and etanercept as adjunctive agents. Clin Exp Rheumatol. 2006;24(5 Suppl 42):S99-103.

22. Sakallioglu O, Duzova A, Ozen S. Etanercept in the treatment of arthritis in a patient with familial Mediterranean fever. Clin Exp Rheumatol. 2006;24(4):435-437.

23. Mor A, Pillinger MH, Kishimoto M, Abeles AM, Livneh A. Familial Mediterranean fever successfully treated with etanercept. J Clin Rheumatol. 2007;13(1):38-40.

24. Metyas S, Arkfeld DG, Forrester DM, Ehresmann GR. Infliximab treatment of Familial Mediterranean fever and its effect on secondary AA amyloidosis. J Clin Rheumatol. 2004;10(3):134-137.

25. Erten S, Erten SF, Altunoglu A. Successful treatment with anti-tumor necrosis factor (anti-TNF)-alpha of proteinuria in a patient with familial Mediterranean fever (FMF) resistant to colchicine: anti-TNF drugs and FMF. Rheumatol Int. 2012;32(4):1095-1097.

26. MacEwan DJ. TNF ligands and receptors--a matter of life and death. Br J Pharmacol. 2002;135(4):855-875.

27. Grell M, et al. The transmembrane form of tumo necrosis factor is the prime activating ligand of the $80 \mathrm{kDa}$ tumor necrosis factor receptor. Cell. 1995;83(5):793-802.

28. Tartaglia LA, Ayres TM, Wong GH, Goeddel DV. A novel domain within the $55 \mathrm{kd}$ TNF receptor signals cell death. Cell. 1993;74(5):845-853.

29. Grell M, et al. Induction of cell death by tumour necrosis factor (TNF) receptor 2, CD40 and CD30: a role for TNF-R1 activation by endogenous membrane-anchored TNF. EMBO J. 1999;18(11):3034-3043.

30. Shu HB, Takeuchi M, Goeddel DV. The tumor necrosis factor receptor 2 signal transducers TRAF2 and c-IAP1 are components of the tumor necrosis factor receptor 1 signaling complex. Proc Natl Acad Sci U S A. 1996;93(24):13973-13978.

31. Hsu H, Xiong J, Goeddel DV. The TNF receptor 1-associated protein TRADD signals cell death and NF-kappa B activation. Cell. 1995;81(4):495-504.

32. Vandenabeele P, Declercq W, Beyaert R, Fiers W. Two tumour necrosis factor receptors: structure and function. Trends Cell Biol. 1995;5(10):392-399.

33. Rothe M, Sarma V, Dixit VM, Goeddel DV. TRAF2-mediated activation of NF-kappa $\mathrm{B}$ by TNF receptor 2 and CD40. Science. 1995;269(5229):1424-1427.

34. Li X, Yang Y, Ashwell JD. TNF-RII and c-IAP1 mediate ubiquitination and degradation of TRAF2. Nature. 2002;416(6878):345-347.

35. Erickson SL, et al. Decreased sensitivity to tumour-necrosis factor but normal T-cell development in TNF receptor-2-deficient mice. Nature. 1994;372(6506):560-563.

36. Dopp JM, Sarafian TA, Spinella FM, Kahn MA, Shau H, de Vellis J. Expression of the p75 TNF receptor is linked to TNF-induced NFkappaB translocation and oxyradical neutralization in glial cells. Neurochem Res. 2002;27(11):1535-1542.

37. Grell M, Becke FM, Wajant H, Männel DN, Scheurich P. Tumor necrosis factor (TNF) receptor type 2 mediates thymocyte proliferation independently of TNF receptor type 1. Eur JImmunol. 1998;28(1):257-263.

38. Peschon JJ, et al. TNF receptor-deficient mice reveal divergent roles for p55 and p75 in several models of inflammation. JImmunol. 1998;160(2):943-952.

39. Arnett HA, Mason J, Marino M, Suzuki K, Matsushima GK, Ting JP. TNF alpha promotes proliferation of oligodendrocyte progenitors and remyelination. Nat Neurosci. 2001;4(11):1116-1122.

40. Marchetti L, Klein M, Schlett K, Pfizenmaier K, Eisel UL. Tumor necrosis factor (TNF)-mediated neuroprotection against glutamate-induced excitotoxicity is enhanced by N-methyl-D-aspartate receptor activation. Essential role of a TNF receptor 2-mediated phosphatidylinositol 3-kinasedependent NF-kappa B pathway. J Biol Chem. 2004;279(31):32869-32881.

41. Sun X, He X, Tzipori S, Gerhard R, Feng H. Essential role of the glucosyltransferase activity in Clostridium difficile toxin-induced secretion of TNF-alpha by macrophages. Microb Pathog. 2009;46(6):298-305.

42. Celkan T, et al. The anemia of familial Mediterranean fever disease. Pediatr Hematol Oncol. 2005;22(8):657-665.

43. Moldawer LL, et al. Cachectin/tumor necrosis factor-alpha alters red blood cell kinetics and induces anemia in vivo. FASEB J.1989;3(5):1637-1643.

44. Rusten LS, Jacobsen SE. Tumor necrosis factor (TNF)-alpha directly inhibits human erythropoiesis in vitro: role of p55 and p75 TNF receptors. Blood. 1995;85(4):989-996.

45. Voulgari PV, Kolios G, Papadopoulos GK, Katsaraki A, Seferiadis K, Drosos AA. Role of cytokines in the pathogenesis of anemia of chronic disease in rheumatoid arthritis. Clin Immunol. 1999;92(2):153-160.

46. Johnson CS, Pourbohloul SC, Furmanski P. Negative regulators of in vivo erythropoiesis: interaction of IL-1 alpha and TNF-alpha and the lack of a strict requirement for $\mathrm{T}$ or NK cells for their activity. Exp Hematol. 1991;19(2):101-105.

47. van Deuren M, Kroot JJ, Swinkels DW. Time-course analysis of serum hepcidin, iron and cytokines in a C282Y homozygous patient with Schnitzler's syndrome treated with IL-1 receptor antagonist. Haematologica. 2009;94(9):1297-1300.

48. Lee P, Peng H, Gelbart T, Wang L, Beutler E. Regulation of hepcidin transcription by interleukin-1 and interleukin-6. Proc Natl Acad Sci U S A. 2005;102(6):1906-1910.

49. Caux C, Saeland S, Favre C, Duvert V, Mannoni P, Banchereau J. Tumor necrosis factor-alpha strongly potentiates interleukin-3 and granulocyte-macrophage colony-stimulating factor-induced proliferation of human CD34+ hematopoietic progenitor 
cells. Blood.1990;75(12):2292-2298.

50. Moradian MM, et al. Patient management and the association of less common familial Mediterranean fever symptoms with other disorders. Genet Med. 2014;16(3):258-263.

51. Chen X, Wu X, Zhou Q, Howard OM, Netea MG, Oppenheim JJ. TNFR2 is critical for the stabilization of the CD4+Foxp3+ regulatory T. cell phenotype in the inflammatory environment. Jimmunol. 2013;190(3):1076-1084.

52. Chen X, Bäumel M, Männel DN, Howard OM, Oppenheim JJ. Interaction of TNF with TNF receptor type 2 promotes expansion and function of mouse CD4+CD25+ T regulatory cells. Jimmunol. 2007;179(1):154-161.

53. Okubo Y, Torrey H, Butterworth J, Zheng H, Faustman DL. Treg activation defect in type 1 diabetes: correction with TNFR2 agonism. Clin Transl Immunology. 2016;5(1):e56.

54. Witsell AL, Schook LB. Tumor necrosis factor alpha is an autocrine growth regulator during macrophage differentiation. Proc Natl Acad Sci US A. 1993;90(10):4763.

55. Pallai A, et al. Transmembrane TNF- $\alpha$ reverse signaling inhibits lipopolysaccharide-induced proinflammatory cytokine formation in macrophages by inducing TGF- $\beta$ : therapeutic implications. JImmunol. 2016;196(3):1146-1157.

56. Gurung P, Fan G, Lukens JR, Vogel P, Tonks NK, Kanneganti TD. Tyrosine kinase SYK licenses MyD88 adaptor protein to instigate IL-1 $\alpha$-mediated inflammatory disease. Immunity. 2017;46(4):635-648.

57. Gerlach B, et al. Linear ubiquitination prevents inflammation and regulates immune signalling. Nature. 2011;471(7340):591-596.

58. Douglas T, Champagne C, Morizot A, Lapointe JM, Saleh M. The inflammatory caspases- 1 and -11 mediate the pathogenesis of dermatitis in sharpin-deficient mice. JImmunol. 2015;195(5):2365-2373.

59. Gurung P, Sharma BR, Kanneganti TD. Distinct role of IL-1 $\beta$ in instigating disease in Sharpincpdm mice. Sci Rep. 2016;6:36634.

60. McGeough M, Wree A, Pena C, Inzaugarat M, Feldstein A, Hoffman H. A significant role for tumor necrosis factor in Nlrp3 inflammasomeopathies. Pediatr Rheumatol Online J. 2015;13(Suppl_1):O27.

61. McGeough MD, et al. TNF regulates transcription of NLRP3 inflammasome components and inflammatory molecules in cryopyrinopathies. J Clin Invest. 2017;127(12):4488-4497.

62. Gurung P, et al. FADD and caspase- 8 mediate priming and activation of the canonical and noncanonical Nlrp3 inflammasomes. JImmunol. 2014;192(4):1835-1846.

63. Sharma D, Kanneganti TD. Inflammatory cell death in intestinal pathologies. Immunol Rev. 2017;280(1):57-73.
64. Ozgocmen S, Ozçakar L, Ardicoglu O, Kocakoc E, Kaya A, Kiris A. Familial Mediterranean fever responds well to infliximab: single case experience. Clin Rheumatol. 2006;25(1):83-87.

65. Ozgocmen S, Akgul O. Anti-TNF agents in familial Mediterranean fever: report of three cases and review of the literature. Mod Rheumatol. 2011;21(6):684-690.

66. Bilgen SA, et al. Effects of anti-tumor necrosis factor agents for familial Mediterranean fever patients with chronic arthritis and/or sacroiliitis who were resistant to colchicine treatment. JClin Rheumatol. 2011;17(7):358-362.

67. Bowers E, Slaughter A, Frenette PS, Kuick R, Pello OM, Lucas D. Granulocyte-derived TNF $\alpha$ promotes vascular and hematopoietic regeneration in the bone marrow. Nat Med. 2018;24(1):95-102.

68. Rusten LS, Jacobsen FW, Lesslauer W, Loetscher $\mathrm{H}$, Smeland EB, Jacobsen SE. Bifunctional effects of tumor necrosis factor alpha (TNF alpha) on the growth of mature and primitive human hematopoietic progenitor cells: involvement of p55 and p75 TNF receptors. Blood. 1994;83(11):3152-3159.

69. Montecucco F, et al. Tumor necrosis factor-alpha (TNF-alpha) induces integrin CD11b/CD18 (Mac-1) up-regulation and migration to the CC chemokine CCL3 (MIP-1alpha) on human neutrophils through defined signalling pathways. Cell Signal. 2008;20(3):557-568.

70. Bouaouina M, Blouin E, Halbwachs-Mecarelli L, Lesavre P, Rieu P. TNF-induced beta2 integrin activation involves Src kinases and a redoxregulated activation of p38 MAPK. J Immunol. 2004;173(2):1313-1320.

71. Lokuta MA, Huttenlocher A. TNF-alpha promotes a stop signal that inhibits neutrophil polarization and migration via a 38 MAPK pathway. JLeukoc Biol. 2005;78(1):210-219.

72. Marshall D, Dangerfield JP, Bhatia VK, Larbi KY, Nourshargh S, Haskard DO. MRL/lpr lupus-prone mice show exaggerated ICAM-1-dependent leucocyte adhesion and transendothelial migration in response to TNF-alpha. Rheumatology (Oxford) 2003;42(8):929-934.

73. Ebach DR, Riehl TE, Stenson WF. Opposing effects of tumor necrosis factor receptor 1 and 2 in sepsis due to cecal ligation and puncture. Shock. 2005;23(4):311-318.

74. Amar S, Van Dyke TE, Eugster HP, Schultze N, Koebel P, Bluethmann H. Tumor necrosis factor (TNF)-induced cutaneous necrosis is mediated by TNF receptor 1. J Inflamm. 1995;47(4):180-189.

75. Kondo S, Sauder DN. Tumor necrosis factor (TNF) receptor type 1 (p55) is a main mediator for TNF-alpha-induced skin inflammation. Eur J Immunol. 1997;27(7):1713-1718.

76. Sheehan KC, Pinckard JK, Arthur CD, Dehner LP, Goeddel DV, Schreiber RD. Monoclonal antibodies specific for murine p55 and p75 tumor necrosis factor receptors: identification of a novel in vivo role for p75. J Exp Med. 1995;181(2):607-617.

77. Tada Y, et al. Collagen-induced arthritis in TNF receptor-1-deficient mice: TNF receptor- 2 can modulate arthritis in the absence of TNF receptor-1. Clin Immunol. 2001;99(3):325-333.

78. Eugster HP, Frei K, Bachmann R, Bluethmann H, Lassmann H, Fontana A. Severity of symptoms and demyelination in MOG-induced EAE depends on TNFR1. Eur J Immunol. 1999;29(2):626-632.

79. Kontoyiannis D, Pasparakis M, Pizarro TT, Cominelli F, Kollias G. Impaired on/off regulation of TNF biosynthesis in mice lacking TNF AU-rich elements: implications for joint and gut-associated immunopathologies. Immunity. 1999;10(3):387-398.

80. Medvedev AE, Espevik T, Ranges G, Sundan A. Distinct roles of the two tumor necrosis factor (TNF) receptors in modulating TNF and lymphotoxin alpha effects. J Biol Chem. 1996;271(16):9778-9784.

81. Sacca R, Cuff CA, Lesslauer W, Ruddle NH. Differential activities of secreted lymphotoxinalpha3 and membrane lymphotoxin-alpha1beta2 in lymphotoxin-induced inflammation: critical role of TNF receptor 1 signaling. J Immunol. 1998;160(1):485-491.

82. Douni E, Kollias G. A critical role of the p75 tumor necrosis factor receptor (p75TNF-R) in organ inflammation independent of TNF, lymphotoxin alpha, or the p55TNF-R. JExp Med. 1998;188(7):1343-1352.

83. Fontaine V, Mohand-Said S, Hanoteau N, Fuchs C, Pfizenmaier K, Eisel U. Neurodegenerative and neuroprotective effects of tumor necrosis factor (TNF) in retinal ischemia: opposite roles of TNF receptor 1 and TNF receptor 2. J Neurosci. 2002;22(7):RC216.

84. Chopra M, et al. Exogenous TNFR2 activation protects from acute GvHD via host T reg cell expansion. J Exp Med. 2016;213(9):1881-1900.

85. Torrey H, et al. Targeting TNFR2 with antagonistic antibodies inhibits proliferation of ovarian cancer cells and tumor-associated Tregs. Sci Signal. 2017;10(462):eaaf8608.

86. Pasparakis M, Alexopoulou L, Episkopou V, Kollias G. Immune and inflammatory responses in TNF alpha-deficient mice: a critical requirement for TNF alpha in the formation of primary B cell follicles, follicular dendritic cell networks and germinal centers, and in the maturation of the humoral immune response. J Exp Med. 1996;184(4):1397-1411.

87. Cowardin CA, Kuehne SA, Buonomo EL, Marie CS, Minton NP, Petri WA. Inflammasome activation contributes to interleukin-23 production in response to Clostridium difficile. MBio. 2015;6(1):e02386-14.

88. Man SM, et al. The transcription factor IRF1 and guanylate-binding proteins target activation of the AIM2 inflammasome by Francisella infection. Nat Immunol. 2015;16(5):467-475 